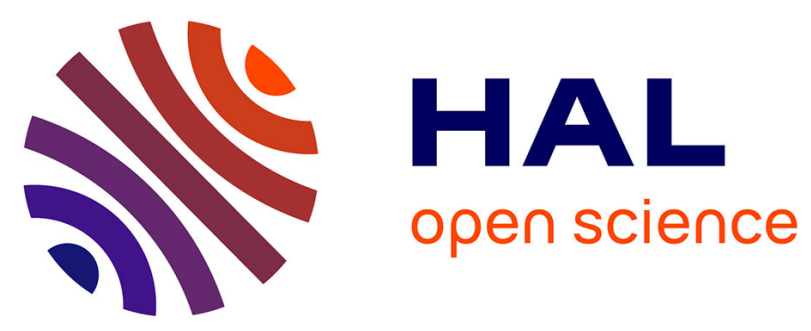

\title{
Stock index realized volatility forecasting in the presence of heterogeneous leverage effects and long range dependence in the volatility of realized volatility
}

Dimitrios Louzis, Spyros Xanthopoulos-Sisinis, Apostolos Refenes

\section{- To cite this version:}

Dimitrios Louzis, Spyros Xanthopoulos-Sisinis, Apostolos Refenes. Stock index realized volatility forecasting in the presence of heterogeneous leverage effects and long range dependence in the volatility of realized volatility. Applied Economics, 2011, pp.1. 10.1080/00036846.2011.577025 . hal-00709559

\section{HAL Id: hal-00709559 \\ https://hal.science/hal-00709559}

Submitted on 19 Jun 2012

HAL is a multi-disciplinary open access archive for the deposit and dissemination of scientific research documents, whether they are published or not. The documents may come from teaching and research institutions in France or abroad, or from public or private research centers.
L'archive ouverte pluridisciplinaire HAL, est destinée au dépôt et à la diffusion de documents scientifiques de niveau recherche, publiés ou non, émanant des établissements d'enseignement et de recherche français ou étrangers, des laboratoires publics ou privés. 


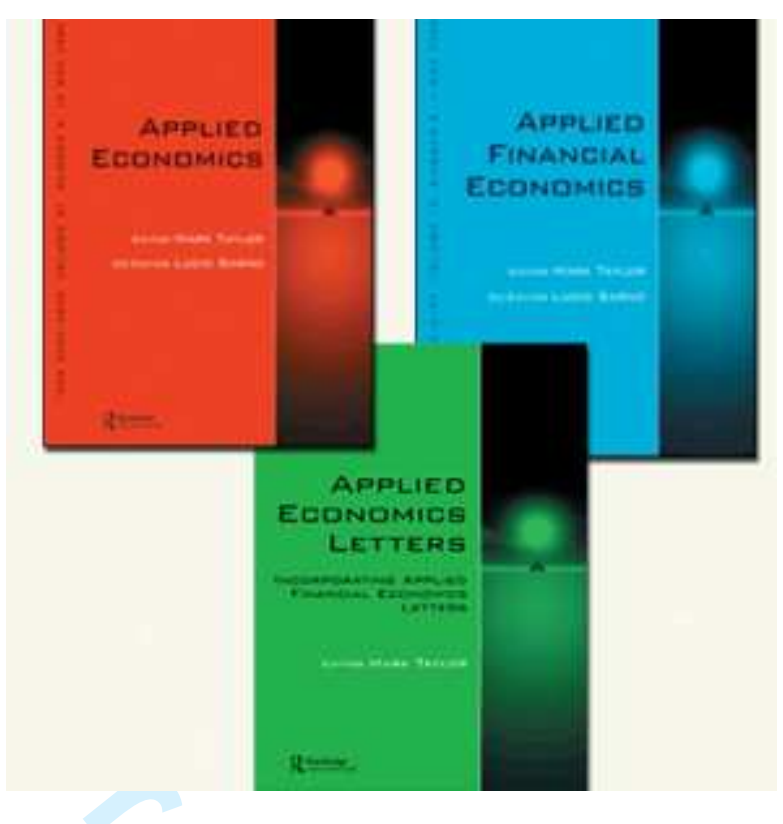

\section{Stock index realized volatility forecasting in the presence of heterogeneous leverage effects and long range dependence in the volatility of realized volatility}

\begin{tabular}{|c|c|}
\hline Journal: & Applied Economics \\
\hline Manuscript ID: & APE-2010-0292.R1 \\
\hline Journal Selection: & Applied Economics \\
\hline $\begin{array}{r}\text { Date Submitted by the } \\
\text { Author: }\end{array}$ & 15-Sep-2010 \\
\hline Complete List of Authors: & $\begin{array}{l}\text { Louzis, Dimitrios; Athens University of Economics and Business, } \\
\text { Management Science and Technology; Bank of Greece, Financial } \\
\text { Stability Department } \\
\text { Xanthopoulos-Sisinis, Spyros; Athens University of Economics and } \\
\text { Business, Management Science and Technology } \\
\text { Refenes, Apostolos; Athens University of Economics and Business, } \\
\text { Management Science and Technology }\end{array}$ \\
\hline JEL Code: & $\begin{array}{l}\text { C13 - Estimation < C1 - Econometric and Statistical Methods: } \\
\text { General < C - Mathematical and Quantitative Methods, C22 - Time- } \\
\text { Series Models < C2 - Econometric Methods: Single Equation Models } \\
<\text { C - Mathematical and Quantitative Methods, C51 - Model } \\
\text { Construction and Estimation < C5 - Econometric Modeling < C - } \\
\text { Mathematical and Quantitative Methods, C53 - Forecasting and } \\
\text { Other Model Applications < C5 - Econometric Modeling < C - } \\
\text { Mathematical and Quantitative Methods }\end{array}$ \\
\hline
\end{tabular}




\title{
Stock index realized volatility forecasting in the presence of heterogeneous leverage effects and long range dependence in the volatility of realized volatility
}

\author{
Stock index realized volatility forecasting \\ Dimitrios P. Louzis ${ }^{\mathrm{a}, \mathrm{b}}$, Spyros Xanthopoulos-Sisinis ${ }^{\mathrm{a}, *}$ and Apostolos P. Refenes ${ }^{\mathrm{a}}$
}

In this article, we account for the presence of heterogeneous leverage effects and the persistence in the volatility of stock index realized volatility. The Heterogeneous Autoregressive (HAR) realized volatility model is extended in order to account for asymmetric responses to negative and positive shocks occurring at distinct frequencies, as well as, for the long range dependence in the heteroscedastic variance of the residuals. Compared with established HAR and Autoregressive Fractionally Integrated Moving Average (ARFIMA) realized volatility models, the proposed model exhibits superior in-sample fitting, as well as, out-of-sample volatility forecasting performance. The latter is further improved when the realized power variation is used as a regressor, while we show that our analysis is also robust against microstructure noise.

${ }^{a}$ Financial Engineering Research Unit, Department of Management Science and Technology, Athens University of Economics and Business, 47A Evelpidon Str., 11362 Athens, Greece

${ }^{\mathrm{b}}$ Bank of Greece, Financial Stability Department, Market Risk Section, 3 Amerikis Str. GR 105 64, Athens, Greece. Note: the views expressed in this article, do not necessarily represent the views of the Bank of Greece

*Corresponding author: E-mail: xanthopo@aueb.gr

The authors would like to thank the two anonymous referees for their helpful comments. 
"A volatility model must be able to forecast volatility; this is the central requirement in almost all financial applications.”, Engle and Patton (2001). Indeed, everyday core business functions such as Basel II capital adequacy calculations, risk management, capital allocation, derivatives pricing and hedging, rely on accurate volatility estimation and forecasting. A plethora of volatility implementations have been proposed in the extant literature, e.g. see Poon and Granger (2003) for a good review. In Andersen and Bollerslev (1998), the authors showed that the daily unobserved volatility could be adequately approximated by the sum of squared intraday returns, the so-called, realized volatility $^{1}$. As evidence appeared that realized volatility possessed long memory, a number of researchers employed the Autoregressive Fractionally Integrated Moving Average (ARFIMA) specification for its modelling (e.g. see Andersen et al., 2003; Giot and Laurent, 2004; Koopman et al., 2005; Noh and Kim, 2006; Degiannakis, 2008; Martens et al., 2009).

An alternative implementation, based on the Heterogeneous Market Hypothesis and Muller's et al. (1997) HARCH model, the Heterogeneous Autoregressive Realized Volatility model (HAR-RV, referred to as HAR henceforth) was also proposed by Corsi (2009). The HAR model utilized volatility components of different time resolutions in order to capture the long memory property of realized volatility in a more straightforward manner. Its tractable estimation and good volatility forecasting performance encouraged its use in several econometric studies e.g., see Andersen et al. (2007) on stock, exchange rate and bond price volatility forecasting, Forsberg and

\footnotetext{
1 The sum of squared intraday returns is actually the realized variance. Realized volatility is defined as the square root of realized variance. However, many authors use the term realized volatility interchangeably with the term realized variance.
} 
Ghysels (2007) and Martens et al. (2009) on volatility forecasting and Clements et al. (2008) on Value at Risk applications.

We contribute to this growing literature by introducing a logarithmic HAR model with asymmetries, or leverage effects ${ }^{2}$, modelled here as lagged standardized returns and absolute standardized returns (analogous to an EGARCH-type structure ${ }^{3}$ ), occurring at distinct time horizons: daily, weekly and monthly. Moreover, in order to capture any remaining long range dependence in the volatility of realized volatility, we propose a Fractionally Integrated GARCH (FIGARCH) implementation for the conditional heteroscedasticity of the residuals. We also apply the Realized Power Variation (RPV), proposed by Barndorff-Nielsen and Shephard (2004) as a regressor, which has been shown to be a robust to jumps, more persistent and accurate predictor of future volatility than realized volatility. As far as we are aware, this is the first time a HAR model with RPV regressors is combined with heterogeneous asymmetric effects and a FIGARCH specification for the residuals. Finally, the robustness of our findings to microstructure noise is assessed using the Two-Times Scale (TTS) volatility estimator of Zhang et al. (2005) which consistently estimates the integrated variance in the presence of microstructure noise.

The proposed model is initially estimated using two ten year data sets from the S\&P 500 and DJIA stock indices. We find that against eight alternative HAR and ARFIMA models, the proposed model produces superior in-sample fitting revealing that not only past negative daily, but also weekly and monthly negative shocks yield a greater impact

\footnotetext{
2 "Bad news" in a stock market (i.e. negative returns) tend to increase future volatility more than "good news" (i.e. positive returns). This asymmetry between negative and positive returns is referred to as asymmetric or leverage effect. In theory, the leverage of the company increases as its stock price goes down, i.e. the company uses more debt than owned capital to finance its business activities. This increases the risk of investing in this stock which in turn increases its volatility.

${ }^{3}$ The asymmetric behavior between returns and volatility is well documented in the GARCH literature. For the use of asymmetric GARCH models in forecasting volatility see Kisinbay (2008).
} 
on current volatility than positive ones, suggesting a heterogeneous component structure in asymmetric effects. Moreover, an interesting contribution of past monthly positive shocks is also identified. Although the inclusion of leverage effects in the HAR regression reduces both the skewness and the heteroskedasticity of the error term, it does not eliminate the ARCH effects. Through Exact Local Whittle (ELW) and Maximum Likelihood Estimation (MLE) integration order estimations, the suspected long range dependence in the volatility of realized volatility is also verified.

The out-of-sample one day ahead, five and twenty-two days ahead forecasting performance is then evaluated for seven established loss functions, as well as with Hansen's (2005) Superior Predictive Ability (SPA) test. The proposed specification minimizes the majority of the loss functions, for both indices and for all the forecasting horizons. Its volatility forecasting performance is further improved when the RPV is included as a regressor, while its superiority is also confirmed by the SPA test $p$-values. Finally, the TTS estimated realized volatility forecasting results underline its robustness against the microstructure noise in the returns process.

The remaining of this article is organized as follows: In Section II we introduce the realized volatility measures and the mathematical notations and definitions used throughout this article. In Section III we present the HAR and ARFIMA based models, while the data set, descriptive statistics and the in-sample maximum likelihood models estimation are shown in Section IV. In Section V, we present the out-of sample realized volatility forecasting evaluation methodology and results. Section VI summarizes and concludes this article.

\section{Realized volatility measures}


In Andersen and Bollerslev (1998), the authors defined realized variance as the sum of squared intraday returns and proved it is an unbiased and less noisy estimator for the daily unobserved volatility, than the squared daily returns proxy (for a good review on realized volatility see McAller and Medeiros, 2008). Let us define the $\mathrm{m}^{\text {th }}$ intraday return for day $\mathrm{t}$ as $r_{m, t}=100 \times\left(\log \left(P_{m, t}\right)-\log \left(P_{m-1, t}\right)\right)$ with $m=1, \ldots, M$, where $M$ is the total number of intraday returns. The first and last price levels observed at day $t$ are denoted as $P_{0, t}$ and $P_{M, t}$ respectively, while the overnight return, or "sleepage", is defined as $r_{0, t}=100 \times\left(\log \left(P_{0, t}\right)-\log \left(P_{M, t-1}\right)\right)$. Since these close-to-open price levels are often in practice quite different, the overnight returns could bias the realized variance estimation and hence the following scaling is applied:

$$
\sigma_{R V, t}^{2}=\left[\left(\sigma_{o c}^{2}+\sigma_{c o}^{2}\right) / \sigma_{o c}^{2}\right] \sum_{m=1}^{M} r_{m, t}^{2}
$$

where $\sigma_{o c}^{2}$ and $\sigma_{c o}^{2}$ are the "open-to-close" and "close-to-open" sample variances respectively, which in turn are computed from $\sigma_{o c}^{2}=(1 / T) \sum_{t=1}^{T}\left[\log \left(P_{M, t}\right)-\log \left(P_{0, t}\right)\right]^{2}$ and $\sigma_{c o}^{2}=(1 / T) \sum_{t=1}^{T}\left[\log \left(P_{0, t}\right)-\log \left(P_{M, t-1}\right)\right]^{2}$ (see Martens, 2002; Koopman et al., 2005 and Degiannakis, 2008). The realized volatility is simply the square root of the realized variance, i.e. $\sigma_{R V, t}=\sqrt{\sigma_{R V, t}^{2}}$. Since realized volatility is an observable variable, standard time series techniques can be used for forecasting purposes.

The intraday sampling frequency used in this article is five minutes, which for liquid assets like the S\&P 500 and the DJIA stock indices it has been found to be the highest sampling frequency with acceptable market microstructure bias (see Andersen et al., 2001a; Koopman et al., 2005; Corsi et al., 2008). Moreover, in order to verify the robustness of our findings against microstructure noise, we repeat our analysis 


\section{The realized volatility models}

\section{Heterogeneous Autoregressive (HAR) models for realized volatility}

Based on the Heterogeneous Market Hypothesis ${ }^{4}$ and the HARCH model ${ }^{5}$, Corsi (2009) proposed an approximate long memory model for realized volatility, the Heterogeneous Autoregressive (HAR) Realized Volatility model. The author suggested that a significant contributor to the market's heterogeneity was the presence of three types of market agents with different time investment horizons: short (daily), medium (weekly) and long term (monthly) investment horizons. Short-term traders (such as hedge funds, FX and statistical arbitrage traders) typically adjust their market positions intradaily, swiftly reacting to any relevant new information. Medium and long-term investors (such as commercial banks and pension funds) have longer holding periods and restructure their trading portfolios according to lower frequency information flow. This asymmetry leads to a hierarchic structure of volatility components, where low (e.g.

\footnotetext{
${ }^{4}$ The Heterogeneous Market Hypothesis (Muller et al., 1993) states that market agents differ with respect to their investment horizon, risk aversion, degree of available information, institutional constraints, transaction costs, etc. This diversity is identified as the root cause of asset volatility, as market agents aim to settle at different asset valuations, according to their individual market view, preferences and expectations.

${ }^{5}$ For practical applications of the HARCH model see McMillan and Speight (2006a) and McMillan and Speight (2006b).
} 
monthly) frequency volatility components should yield a greater impact on the overall volatility than high (e.g. daily) frequency volatility components. The economic rationale is that short-term investors interpret the level of long-term volatilities as predictions of future volatility and adjust their trading strategies accordingly, while short-term volatility is irrelevant to investors with longer holding periods. Corsi showed that by aggregating daily, weekly and monthly volatility components in an autoregressive structure, one could capture the heterogeneity of realized volatility, whilst approximating its long range dependence properties.

Here, in order to mitigate any positivity restrictions on the model's parameters and error term (e.g. see Andersen et al., 2003), we will use the logarithm of the realized volatility in the HAR implementation:

$$
\operatorname{lr} v_{t}^{(d)}=a_{0}+a_{(d)} l r v_{t-1}^{(d)}+a_{(w)} \operatorname{lr} v_{t-1}^{(w)}+a_{(m)} l r v_{t-1}^{(m)}+u_{t}
$$

where $\operatorname{lr} v_{t}^{(d)}=\log \left(\sigma_{R V, t}^{2}\right)$ is the daily logarithmic realized variance, $u_{t}$ are the errors distributed as $N\left(0, \sigma_{u}^{2}\right)$ since $\operatorname{lr} v_{t}^{(d)}$ is approximate normal (e.g. see Andersen et al., 2003), $\operatorname{lr} v_{t-1}^{(w)}=\left(\frac{1}{5}\right) \sum_{i=1}^{5} \operatorname{lr} v_{t, t-i}^{(d)}$ and $\operatorname{lr} v_{t-1}^{(m)}=\left(\frac{1}{22}\right) \sum_{i=1}^{22} \operatorname{lr} v_{t, t-i}^{(d)}$ are the lagged weekly and monthly volatility components respectively, computed for each day $t$ as a moving average of the previous five and twenty-two days daily logarithmic realized volatilities respectively. We anticipate that some informational content in the individual lags of the logarithm of realized volatility could as a result of the averaging be lost, however empirical evidence has shown that the embedded long lag structure of the HAR model, equivalent to a restricted $\operatorname{AR}(22)^{6}$, is capable of reproducing the long memory behavior of realized volatility (Corsi, 2009; Martens et al., 2009). Moreover, the simple

\footnotetext{
${ }^{6}$ For the use of AR models in realized volatility forecasting see Hooper et al. (2009)
} 
autoregressive functional form of the HAR model requires no more than OLS for the estimation of its parameters.

In Corsi et al. (2008), the authors proposed a $\operatorname{GARCH}(p, q)$ error process in order to account for the time varying conditional heteroscedasticity of the normally distributed HAR errors, i.e. the so called "volatility of realized volatility":

$$
\begin{gathered}
\operatorname{lr} v_{t}^{(d)}=a_{0}+a_{(d)} \operatorname{lr} v_{t-1}^{(d)}+a_{(w)} \operatorname{lr} v_{t-1}^{(w)}+a_{(m)} \operatorname{lr} v_{t-1}^{(m)}+u_{t} \\
u_{t}=\sigma_{u, t} \varepsilon_{t} \text { and } \sigma_{u, t}^{2}=\omega+\alpha(L) u_{t}^{2}+\beta(L) \sigma_{u, t}^{2}
\end{gathered}
$$

where $\varepsilon_{t} \mid I_{t-1} \sim N(0,1), I_{t-1}$ is the information available until $t-1, L$ is the lag operator $\left(L y_{t}=y_{t-1}\right), \alpha(L)=\alpha_{1} L+\alpha_{2} L^{2}+\ldots+\alpha_{p} L^{p}$ and $\beta(L)=\beta_{1} L+\beta_{2} L^{2}+\ldots+\beta_{q} L^{q}$ are the lag polynomials of orders $p$ and $q$ respectively.

Corsi and Reno (2009) also included past negative daily, weekly and monthly returns as regressors in the HAR model, aiming to capture the leverage effects in the volatility process, plus a jump component. Finally, the authors in Andersen et al. (2007) proposed a HAR model with a jump component and found that the latter had restricted persistence compared with the continuous part of the quadratic variation, i.e. its contribution to forecasting volatility was limited.

\section{The Asymmetric HAR-(FI)GARCH models}

In this article, we propose extending the HAR specification towards three directions. Firstly, we adopt a more flexible EGARCH-type structure for implementing the asymmetries in the volatility process. We expand the HAR model of Equation (2) in order to include standardized and absolute standardized returns aggregated over different time resolutions. Here, we consider the complete returns dataset in the 
analysis, thus allowing for asymmetric responses to both negative and positive shocks. Secondly, through a FIGARCH specification, we account for the long memory of the residual's variance in Equation (4). Finally, we use the Realized Power Variation (RPV) as a regressor, which has been shown to be robust to jumps and a more persistent and accurate predictor of future volatility than realized volatility, see Ghysels et al. (2006) and Forsberg and Ghysels (2007).

Initially, the asymmetric dynamics of past daily positive and negative returns are introduced. The Asymmetric (daily) HAR (hereafter AdHAR) model with daily leverage effects is defined as follows:

$$
\operatorname{lr} v_{t}^{(d)}=a_{0}+a_{(d)} l r v_{t-1}^{(d)}+a_{(w)} l r v_{t-1}^{(w)}+a_{(m)} l r v_{t-1}^{(m)}+\vartheta_{(d)} z_{t-1}^{(d)}+\gamma_{(d)}\left|z_{t-1}^{(d)}\right|+u_{t}(5)
$$

where $z_{t}^{(d)}=r_{t} / \sigma_{R V, t}$ are the daily standardized returns. Equation (5) can be extended in order to account for the heterogeneity in asymmetric effects, i.e. asymmetric volatility reactions not only to past daily but also to weekly and monthly standardized returns. The Asymmetric HAR (AHAR) is given by:

$$
\begin{aligned}
\operatorname{lr} v_{t}^{(d)} & =a_{0}+a_{(d)} l r v_{t-1}^{(d)}+a_{(w)} l r v_{t-1}^{(w)}+a_{(m)} l r v_{t-1}^{(m)}+ \\
& +\vartheta_{(d)} z_{t-1}^{(d)}+\vartheta_{(w)} z_{t-1}^{(w)}+\vartheta_{(m)} z_{t-1}^{(m)}+ \\
& +\gamma_{(d)}\left|z_{t-1}^{(d)}\right|+\gamma_{(w)}\left|z_{t-1}^{(w)}\right|+\gamma_{(m)}\left|z_{t-1}^{(m)}\right|+u_{t}
\end{aligned}
$$

where $z_{t}^{(h)}=\sum_{i=1}^{h} r_{t-i+1} / \sqrt{\sum_{i=1}^{h} \sigma_{R V, t-i+1}^{2}}$ are the daily $(h=d=1)$, weekly $(h=w=5)$ and monthly $(h=m=22)$ standardized returns. The response of the logarithmic realized variance to past positive and negative standardized returns is given by:

$$
\frac{\partial l r v_{t}^{(d)}}{\partial z_{t-1}^{(\cdot)}}= \begin{cases}\vartheta_{(\cdot)}+\gamma_{(\cdot)}, & \text { if } z_{t-1}^{(\cdot)}>0 \\ \vartheta_{(\cdot)}-\gamma_{(\cdot)}, & \text { if } z_{t-1}^{(\cdot)}<0\end{cases}
$$

The leverage effects are captured by the coefficient $\vartheta_{(\cdot)}$ which is expected to be negative and statistically different from zero, should past negative shocks yield a greater impact on future volatility. 
Although accounting for leverage effects in Equation (6), may lead to some reduction in the skewness of the errors, the heteroscedasticity in the residuals is expected to remain due to the variance of the realized volatility estimator (Corsi et al., 2008). A straightforward approach, is to implement a $\operatorname{GARCH}(p, q)$ error process to account for the conditional heteroscedasticity of the HAR residuals, in an AHARGARCH model.

We suspect however that the residuals could still retain the long memory property of realized volatility. Motivated by the findings of Beltratti and Morana (2005) (see ARFIMA models below), we propose to model the residuals with a $\operatorname{FIGARCH}\left(m, d_{u}, q\right)$ specification (see Baillie et al., 1996), implemented as:

$$
\sigma_{u, t}^{2}=\omega+\beta(L) \sigma_{u, t}^{2}+\left\{1-\beta(L)-\varphi(L)(1-L)^{d_{u}}\right\} u_{t}^{2}
$$

The FIGARCH model captures the long memory behavior of the variance process through the long memory, or fractional differencing parameter, $d_{u}$, and is essentially an ARFIMA implementation of the squared residuals in Equation (6). For values of the differencing parameter $d_{u}$ between 0 and 1 , the autocorrelation of the volatility process exhibits a slow hyperbolic rate of decay. As the term $(1-L)^{d_{u}}$ in Equation (8) is an infinite summation, the FIGARCH obtains an infinite order specification, which in practice is truncated at 1000 lags, as suggested in Baillie et al. (1996).

The Realized Power Variation

Recently, the Realized Power Variation (RPV) proposed by Barndorff-Nielsen and Shephard (2004), has been found to produce superior realized volatility forecasts when implemented as a reggresor in a HAR model. The RPV of order $p$, is defined as: 


$$
R P V_{t}(p)=\mu_{z}^{-1} M^{-(1-p / 2)} \sum_{m=1}^{M}\left|r_{m, t}\right|^{p}
$$

where $0<p<2, \mu_{z}=E|z|^{p}=2^{p / 2} \Gamma\left(\frac{1}{2}(p+1)\right) / \Gamma\left(\frac{1}{2}\right)$ with $z \sim N(0,1)^{7}$. Forsberg and Ghysels (2007), Ghysels et al. (2006) and Ghysels and Sinko (2006) demonstrated the ability of realized absolute variation, i.e. RPV(1), to produce superior volatility forecasts compared to the squared return volatility measures. They argued that the RPV is a better predictor of realized volatility because of its robustness to jumps, its smaller sampling error and its improved predictability. Here, following Liu and Maheu (2009) and Fuertes et al. (2009), who showed that an RPV of order other than one can significantly improve the accuracy of volatility forecasts, we use a RPV of order 1.5 as a regressor in the HAR models presented above. Hence, the simple HAR-RPV model is defined as:

$$
\operatorname{lr} v_{t}^{(d)}=a_{0}+a_{(d)} \operatorname{lrp} v_{t-1}^{(d)}+a_{(w)} \operatorname{lrp} v_{t-1}^{(w)}+a_{(m)} l r p v_{t-1}^{(m)}+u_{t}
$$

where $\operatorname{lrp} v_{t}^{(d)}=\log \left(R P V_{t}\right)$ is the RPV daily logarithm and $\operatorname{lrp} v_{t-1}^{(w)}$ and $\operatorname{lrp} v_{t-1}^{(m)}$ are the respective five and twenty days logarithm RPV moving average components for each day $t$. The other HAR models are analogously defined.

\section{ARFIMA models for realized volatility}

The application of ARFIMA models for realized volatility modelling and forecasting purposes was first proposed by Andersen et al. (2001a) and Andersen et al. (2003), based on the analysis of Granger (1980) and Granger and Joyeux (1980). Since

\footnotetext{
${ }^{7}$ Note that when $p=2$, the RPV is by definition equal to the realized volatility (i.e. $R P V_{t}(2) \equiv \sigma_{R V, t}^{2}$ ). In this case, the RPV is not robust to jumps and converges to the integrated volatility plus the jump component.
} 
then, a number of ARFIMA based models have been proposed for volatility forecasting applications, most with good results (e.g. see Andersen et al., 2003; Pong et al., 2004 and Koopman et al., 2005). We will thus include in this study some of the more relevant ARFIMA models, in order to provide a straightforward comparison to the HAR based model proposed above.

ARFIMA models are genuine long memory time series models which describe the stochastic behavior of a fractionally integrated variable using autoregressive and moving average components. The basic $\operatorname{ARFIMA}\left(r, d_{R V}, l\right)$ model for the logarithm of the realized volatility, in terms of deviations from the mean, $\mu$, is defined as:

$$
(1-\psi(L))(1-L)^{d_{R V}}\left(\operatorname{lr} v_{t}^{(d)}-\mu\right)=(1+\delta(L)) u_{t}
$$

where $d_{R V}$ is the fractionally differencing parameter of the logarithmic realized variance and $u_{t} \sim N\left(0, \sigma_{u}\right)$ as in (2). Beltratti and Morana (2005) first considered the conditional heteroscedasticity in the ARFIMA errors by proposing an

$$
\begin{gathered}
\operatorname{ARFIMA}\left(r, d_{R V}, l\right)-\operatorname{FigARCH}\left(m, d_{u}, q\right) \text { model: } \\
\qquad \begin{array}{c}
(1-\psi(L))(1-L)^{d_{R V}}\left(\operatorname{lr} v_{t}^{(d)}-\mu\right)=(1+\delta(L)) u_{t} \\
u_{t}=\sigma_{u, t} \varepsilon_{t}
\end{array}
\end{gathered}
$$

where $\sigma_{u, t}$ is modeled as in Equation (8). In order to capture the asymmetric effects, lagged returns and indicator functions have been utilized as explanatory variables of the mean (ARFIMAX models), e.g. see Andersen et al. (2001a), Thomakos and Wang (2003), Giot and Laurent (2004), Angelidis and Degiannakis (2008). Here, we implement lagged (absolute) daily standardized returns, along with a FIGARCH structure for the conditional heteroscedasticity of the errors, thus defining the $\operatorname{ARFIMAX}\left(r, d_{R V}, l\right)-\operatorname{FIGARCH}\left(m, d_{u}, q\right)$ as:

$$
(1-\psi(L))(1-L)^{d_{R V}}\left(\operatorname{lr} v_{t}^{(d)}-\mu-\vartheta_{(d)} z_{t-1}^{(d)}-\gamma_{(d)}\left|z_{t-1}^{(d)}\right|\right)=(1+\delta(L)) u_{t}(14)
$$


where $z_{t}^{(d)}=r_{t} / \sigma_{R V, t}$ are the daily standardized returns and $\sigma_{u, t}$ is a FIGARCH specification (see Equation (8)). The asymmetric effect is captured by $\vartheta_{(d)}$, which is expected to be negative and statistically different from zero.

\section{The data set, descriptive statistics and model estimation}

The data set was obtained from Tick Data and consists of five minutes previous tick interpolated prices, $P_{m, t}$, for the S\&P 500 and the DJIA cash indices over a ten year period, from 1.1.1997 to 12.31.2006. After adjustments for holidays and half-holidays, there were $T=2,508$ trading days per index, with six and a half trading hours per day, interpreted as $M=78$ intraday returns. Each full data set, was divided into $T^{*}=1,508$ in-sample observations, from 31.01.1997 to 30.12.2002 and $n=T-T^{*}=1,000$ out-ofsample observations.

Descriptive statistics and stylized facts

The descriptive statistics for the daily logarithmic returns ${ }^{8}$, daily standardized returns, realized variance and logarithmic realized variance for the two full data sets are shown in Table 1. Both original return series have negative skewness and fat tails, a departure from normality which can be attributed to mainly negative price shocks near the end of 1997 and 1998, all through 2000 and towards the end of 2002. The skewness and kurtosis of the standardized returns and of the logarithmic variance series as well as

\footnotetext{
${ }^{8}$ The daily logarithmic returns are calculated as $r_{t}=100 \times\left(\log \left(P_{M, t}\right)-\log \left(P_{M, t-1}\right)\right)$ where $P_{M, t},\left(P_{M, t-1}\right)$ is the closing price of day $t,(t-1)$.
} 
the normality tests suggest that the respective distributions are approximately normal, a conclusion similar as in Andersen et al. (2001a) and Andersen et al. (2001b).

\section{Insert Table 1}

The fractional integration order of the logarithmic realized variance series is calculated using the Exact Local Whittle (ELW) estimator proposed by Shimotsu and Philips (2005). The estimator relies on the frequency domain representation of the observed series, as expressed by its Discrete Fourier Transform (DFT) and evaluated at $m$ Fourier frequencies from the spectrum's origin. A widely adopted functional form for $m$ is $m=T^{\mu}$ with $0<\mu<1$, while the empirical evidence suggests that values for $\mu$ in the interval $[0.5,0.6]$ limit the bias and variance of the integration order estimate. The logarithmic realized variance ELW integration order estimates for both indices are shown in Fig. 1 for $\mu \in[0.4,0.7]$. The $d_{R V}$ estimates vary between 0.55 and 0.6 , suggesting that the realized variance follows a covariance non-stationary fractionally integrated process.

\section{Insert Fig. 1}

Finally, the descriptive statistics and stylized facts for the two indices for the TTS estimated realized variance show no significant departure from the aforementioned squared intraday returns observations and are available from the authors upon request.

Estimation of the HAR based models 
Before proceeding with the parameters estimation ${ }^{9}$, the optimum lag order for the AHAR-FIGARCH model was first determined. The lag structure combinations which minimized the AIC and SIC criteria were an AHAR-FIGARCH $\left(1, d_{v}, 1\right)$ and an AHARFIGARCH $\left(0, d_{u}, 0\right)$ for the S\&P 500 and DJIA indices respectively. The coefficient estimates for all the HAR based models, as well as the respective in-sample diagnostics are summarized in Tables 2 and 3 for the S\&P 500 and DJIA indices respectively.

\section{Insert Table 2}

\section{Insert Table 3}

For the HAR, HAR-GARCH and AdHAR models, the coefficient of the lagged weekly volatility component, $a_{(w)}$, bears the greatest impact on current volatility, followed by the daily volatility component, while the monthly one influences the total volatility significantly less. Hence, the day-ahead volatility appears to be the aggregate effect of short and mostly medium term volatility components and much less of longer term volatility factors. However, when the heterogeneity of the leverage effects is taken into consideration in the AHAR based models (i.e. in the AHAR, AHAR-GARCH and AHAR-FIGARCH models), the balance shifts drastically. Now, past longer horizon volatility events (weekly and monthly volatility components) appear to primarily shape the indices future volatility, a conclusion which is in agreement with the economic rationale laid out in Section III. The discussion of the estimation results in terms of the leverage effects and the presence of long memory in the residuals is next presented.

9 All estimates were deduced by numerical optimization of the log likelihood function (Maximum Likelihood Estimation, MLE) and they were conducted with the Ox Metrics G@RCH 4.2 package developed by Laurent and Peters (2002). 
The leverage effects

For both indices, accounting for daily leverage effects in the AdHAR model leads to a reduction in the residuals' skewness and a significant improvement in the goodness of fit indicators (i.e. A(S) Information Criteria). However, there is still evidence of ARCH effects in the residuals of both indices, as the ARCH-LM tests suggest. For the DJIA index, the inclusion of weekly and monthly standardized returns in the AHAR model reduces the skewness of the errors, while there is also evidence in favor of the rejection of the ARCH effects hypothesis. This is also reflected in the GARCH coefficients estimates of the AHAR-GARCH model for the DJIA index, where none of them are statistical significant at a 5\% significance level.

The coefficients of the lagged daily, weekly and monthly standardized returns, $\vartheta_{(\cdot)}$, in the AHAR based models are all statistically significant at a 1\% significance level, confirming that future market volatility will react asymmetrically not only to yesterday's negative returns, but also to past weekly and monthly returns. Their negative weighting also suggests that past negative shocks induce more market volatility than past positive ones. This is clearly depicted in Fig. 2 below, where the impact of past daily, weekly and monthly shocks on future realized volatility is shown.

\section{Insert Fig. 2}

It is clear that past negative return events, irrespective of the time horizon, subscribe to future volatility variations more than positive ones. The volatility contribution hierarchy is analogous to that of the volatility components, with the weekly 
standardized return being the prevailing contributor to the overall volatility, followed by the monthly one. However, it is interesting to note that past positive monthly shocks will also tend to increase volatility, while past positive daily and weekly shocks will have a negative impact on volatility. As far as we are aware, this is a novel finding, underlining the importance of including in the analysis the complete returns dataset and not just past negative returns.

Long range dependence in the residuals

The presence of long memory in the residuals' variance is depicted in Fig. 3, where the ELW fractional differencing parameter estimates, $d_{u}$, for the HAR model squared residuals are shown for $\mu \in[0.4,0.7]$.

\section{Insert Fig. 3}

For both indices, the ELW $d_{u}$ estimates are statistically significant, thus confirming that not only realized volatility, but also the "volatility of realized volatility" is autocorrelated for longer time periods. The presence long memory process in the HAR residuals confirms the suitability of the proposed FIGARCH implementation for their modelling. The AHAR-FIGARCH residuals $d_{u}$ MLE estimates shown in Tables 2 and 3 are very close to the respective HAR squared residuals $d_{u}$ ELW estimates, as expected.

Finally for both indices, there is no noteworthy difference between the TTS realized volatility model coefficient estimates and the ones presented above, confirming the 
robustness of our findings in the presence of microstructure noise (the estimation results are available from the authors upon request).

Estimation of the ARFIMA based models

The estimation results for the ARFIMA based models are shown in Table 4. The lag structures minimizing the $\mathrm{A}(\mathrm{S}) \mathrm{IC}$ information criteria for the ARFIMA models were again determined through testing various lag combinations for $r=\{0,1,2\}, l=\{0,1,2\}$, $m=\{0,1\}$ and $q=\{0,1\}$. For both indices, we adopted the following specifications for the respective models: an $\operatorname{ARFIMA}\left(1, d_{R V}, 0\right)$, an

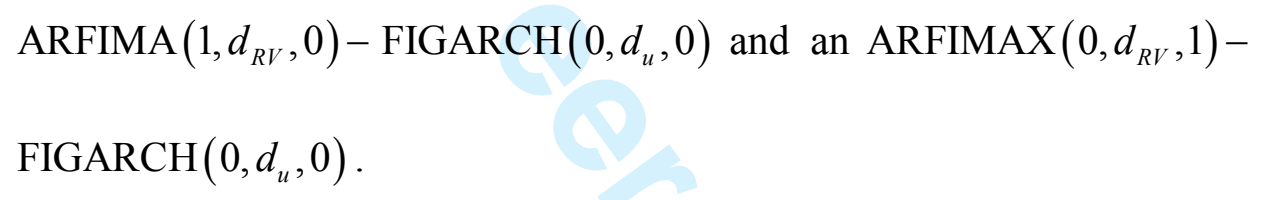

The MLE fractional differencing parameter, $d_{R V}$, estimates vary between 0.49 and 0.58 for both indices, confirming the respective ELW estimation results shown in Fig. 1. Moreover, the long range dependence in the conditional volatility of the ARFIMA residuals is also verified by the respective $d_{u}$ MLE estimates, which for the ARFIMAFIGARCH and ARFIMAX-FIGARCH models range from 0.07 to 0.09 and are statistically significant. Finally, the ARFIMAX-FIGARCH $\vartheta_{(d)}$ and $\gamma_{(d)}$ estimates confirm the asymmetric impact of past negative shocks on future volatility, as $\vartheta_{(d)}$ is negative and statistically significant. 
Overall, amongst the nine HAR and ARFIMA realized volatility models estimated here, the proposed model exhibits for both indices the best overall goodness of fit, as measured by the AIC and SIC criteria. Moreover, for both the HAR and ARFIMA models, when the conditional heteroscedasticity of the residuals and more significantly so the leverage effects are accounted for, the in-sample fitting as determined by the AIC and SIC criteria is considerably improved. Finally, the excess kurtosis values suggest that a more fat tailed distribution than the normal, might have been more appropriate.

\section{Realized volatility forecasting and evaluation}

In order to evaluate the realized volatility forecasting performance, a rolling window of $T^{*}$ observations was used to re-estimate the models and produce $n$ out-of-sample day-ahead realized volatility forecasts calculated as:

$$
E\left(\sigma_{R V, t}^{j} / I_{t-1}\right)=\hat{\sigma}_{R V, t / t-1}^{j}=\left(\exp \left(l \hat{r} v_{t / t-1}^{j}+0.5 \sigma_{u, t / t-1}^{2 j}\right)\right)^{1 / 2}
$$

where $l \hat{r} v_{t / t-1}^{j}$ is the day-ahead logarithmic realized variance forecast and $\sigma_{u, t / t-1}^{2 j}$ is the model $j$ residuals variance ${ }^{10}$, while $n=1,000,996$ and 979 observations for the day ahead, five days and twenty-two days ahead realized volatility forecasts respectively, spanning from the $31^{\text {st }}$ December 2002 to the $29^{\text {th }}$ December 2006. For the five and twenty two days ahead realized volatility forecasts, the corresponding realized volatilities were computed as the square root of the sum of daily realized variances over each forecasting period.

\footnotetext{
10 The transformation in Equation (15) is derived from the realized variance lognormality assumption: A random variable $y_{t}$ is lognormally distributed if $x_{t}=\log y_{t}$ is normally distributed. Then, the expectation of $y_{t}$ is $E\left(y_{t}\right)=\exp \left(\mu+0.5 \sigma^{2}\right)$, with $\mu$ and $\sigma^{2}$ denoting the mean and the variance of $y_{t}$ respectively, e.g. see Beltratti and Morana (2005) and Giot and Laurent (2004).
} 


\section{Realized volatility forecasting evaluation}

In order to evaluate the model's out-of sample realized volatility forecasting performance over the three forecasting horizons, we used the seven loss functions shown in Table 5 below.

\section{Insert Table 5}

MSE and MAE stand for the Mean Square Error and Mean Absolute Error standard loss functions respectively. MAPE is the Mean Absolute Percentage Error and MLAE is the Mean Logarithm of Absolute Errors. The QLIKE criterion proposed by Bollerslev et al. (1994) is the loss implied by a Gaussian likelihood. The R2LOG loss function of Pagan and Schwert (1990) is equivalent to the MSE, but for the logarithm of realized volatility. This loss function applies a greater penalty when forecasting errors occur in low volatility periods, than when they occur in high volatility periods. Using the MSE (R2LOG) criteria is equivalent to testing whether the R-square of the Mincer-Zarnowitz regressions for the (logarithmic) realized volatility of the benchmark model, is always greater than that of its counterparts (Marcucci, 2005). Finally, the HMSE is the Heteroscedastic Mean Squared Error proposed by Bollerslev and Ghysels (1996).

The predictive ability of the realized volatility models was also assessed via Hansen's (2005) Superior Predictive Ability (SPA) test. The SPA test relies on a predetermined loss function in order to test whether the null hypothesis that the benchmark model is not outperformed by any of its competitors, is rejected or not. The forecasting performance of the benchmark model, model 0 , with respect to model $k$ is 
deduced from: $f_{t, k}=L_{t, 0}-L_{t, k}, k=1 . . . l$ and $t=1 \ldots n$. Where $L_{t, j} \equiv L\left(\sigma_{R V, t}, \hat{\sigma}_{R V, t / t-1}^{j}\right)$

with $j=0, k$ is the predetermined forecast loss function of the benchmark model and of model $k$ respectively. Under the null hypothesis and assuming stationarity for $f_{t, k}$, we expect that on average the forecasting loss function of the benchmark model will be smaller, or at least equal to that of model $k$. Thus, the null hypothesis can be stated as: $H_{0}: \max _{k=1 \ldots l} \mu_{k}=E\left(f_{t, k}\right) \leq 0$ and can be tested through the following test statistic:

$$
T_{n}^{S P A}=\max _{k=1 . . . l} \frac{\sqrt{n} \bar{f}_{k}}{\sqrt{\operatorname{var}\left(\sqrt{n} \bar{f}_{k}\right)}}
$$

where $\bar{f}_{k}=(1 / n) \sum_{t=1}^{n} f_{t, k}$ and $\operatorname{var}\left(\sqrt{n} \bar{f}_{k}\right)$ is the variance of $\sqrt{n} \bar{f}_{k}$. Both $\operatorname{var}\left(\sqrt{n} \bar{f}_{k}\right)$ and the test statistic $p$-values are consistently estimated via stationary bootstrapping as in Politis and Romano (1994).

The SPA test analysis focuses only on the MSE and QLIKE loss functions as these two measures have been shown to be robust against volatility proxy noise (see Patton, 2006). Since realized volatility is a proxy for the true unobservable volatility, the aforementioned two loss functions yield consistent model rankings, without however diminishing the informative power of the other loss functions in Table 5.

The models' loss function performance

In Tables 6 and 7, the Table 5 loss functions results, as well as each model's relative performance rankings (in parenthesis) are shown for the S\&P 500 and DJIA stock indices respectively. Across all forecasting horizons, the proposed AHAR-RPVFIGARCH model nearly always ranks first amongst the alternative models, minimizing the respective loss functions, with the exception of the DJIA index twenty-two days 
ahead forecast where the AHAR-RPV-GARCH model ranks first. Note, that for the DJIA index where the persistence in the residuals' variance is smaller than in the S\&P 500 index (e.g. see the Tables 2 and 3 and Fig. 3), the benefit of implementing an explicit long memory volatility specification for the residuals is moderated, especially for longer term forecasts. The AHAR-RPV-GARCH model according to most of the loss functions ranks second for the one and five days ahead forecasting horizons, followed by the AHAR-FIGARCH and the AHAR-GARCH models. For the S\&P 500 index and for the twenty-two days ahead horizon, the AHAR-FIGARCH ranks second (first for the QLIKE and HMSE loss functions), followed by the AHAR-RPV-GARCH and AHAR-GARCH models.

As for the rest HAR and ARFIMA model variations, the HAR models with leverage effects (AdHAR, AHAR) typically outperform the more advanced ARFIMA models (ARFIMA-FIGARCH and ARFIMAX-FIGARCH). However, for the S\&P500 index twenty-two days ahead forecasts, the aforementioned performance ranking is reversed. In turn, the AHAR model consistently outperforms the AdHAR one, underlining again the importance of considering the heterogeneity in the leverage effects.

It is nonetheless clear that even though the inclusion of daily, weekly and monthly (absolute) standardized returns in the HAR regression reduces the heteroscedasticity in the residuals (see the ARCH-LM tests in Tables 2 and 3), a GARCH, or significantly more so, a FIGARCH implementation for the residuals invariably enhances the forecasting performance. Finally, the AFRIMA model performs, par from a few exceptions, better than the HAR-GARCH model, while the basic HAR model is the overall worst performing specification.

\section{Insert Table 6}




\section{Insert Table 7}

From the results synopsis presented above, the following conclusions can be drawn: Firstly, regardless if an RPV regressor is used or not, accounting for asymmetric effects is as important as accounting for their heterogeneity: the AHAR model always outperforms the AdHAR one and the latter consistently outperforms the HAR. Secondly, as expected, we confirm that considering the conditional heteroscedasticity of the realized volatility residuals is essential in volatility modelling and forecasting applications, even with the presence of asymmetric effects in the volatility equation. However, it is now evident that the heteroscedasticity is better accounted for with a FIGARCH implementation which captures the long memory of the variance residuals. The models with a FIGARCH specification for their residuals outperform the respective models with GARCH ones, as almost all the loss functions results suggest. Finally, the RPV is a better predictor of realized volatility than the squared returns measure, significantly improving the volatility forecasting performance when added as a regressor.

The TTS volatility forecast rankings

The out-of-sample volatility forecasting analysis for the HAR based models is once again evaluated using the TTS realized volatility estimates (see Table 8). For both indices and across all forecasting horizons, the AHAR-FIGARCH model outperforms all the other models as it minimizes almost all the loss functions. These results confirm that the aforementioned findings are robust to microstructure noise bias. However, in 
tests run by the authors but not shown here, we noted that the inclusion of the RPV regressor did not significantly improve the model's forecasting ability, when the dependent variable is the TTS realized volatility.

\section{Insert Table 8}

The SPA test results

The SPA test $p$-values for the MSE and QLIKE loss functions are shown in Table 9 and align with the aforementioned findings. When the AHAR-RPV-FIGARCH or the AHAR-RPV-GARCH model is the benchmark model, the null hypothesis of superior performance is strongly accepted (at a 10\% significance level), for both indices and both loss functions, for the short and mid term forecasting horizons (one and five days ahead). When an alternative realized volatility model is chosen as the benchmark model, then the null hypothesis is rejected, implying that another model, or models, produces statistically significant better forecasts.

For the twenty-two days ahead forecast horizon, the null hypothesis is also accepted for the AFRIMA-FIGARCH and ARFIMAX-FIGARCH models, indicating that for longer term forecasts the ARFIMA models are competitive to the HAR models, potentially benefiting by their genuine long memory structure. Overall, the asymmetric RPV models exhibit the best out-of-sample forecasting performance, yielding for both functions the highest $p$-values for almost all the forecast horizons.

\section{Insert Table 9}




\section{Conclusions}

Building on the HAR realized volatility model proposed by Corsi (2009), we captured the leverage effects in the volatility process using (absolute) standardized returns of daily, weekly and monthly frequencies. The HAR error's heteroscedasticity and long memory was also accounted for with a FIGARCH implementation. Moreover, we introduced the RPV as a regressor, which has been shown to be robust to jumps, has a smaller sampling error and is more predictable. In order to examine the robustness of our findings to microstructure noise, we also calculated the realized variance with a TTS estimator and then re-evaluated our models.

The proposed AHAR-FIGARCH model produced the best in-sample fitting against the alternative HAR and ARFIMA based realized volatility models. The estimation results confirmed the appropriateness of our modelling as heterogeneity in the asymmetric effects was established, along with a long range dependence in the volatility's residuals. Rankings of each model's forecasting performance for seven established loss functions were also produced. Overall, the proposed model with the RPV as a regressor (i.e. the AHAR-RPV-FIGARCH), minimized the majority of the forecast loss functions, across all forecasting horizons and indices. The SPA test $p$ values also confirmed that the AHAR-RPV-GARCH model was not, for the most part, outperformed by any other model. The TTS estimated realized volatility forecasting results demonstrated that the proposed model specification is also robust against the microstructure noise in the returns process.

The published evidence so far concurs that despite the predominant economic significance of producing accurate volatility forecasts, there is no single "ideal" volatility model for all markets and for all financial applications. Here, we showed that 
1

2

3

4

5

6

7

8

9

10

11

12

13

14

15

16

17

18

19

20

21

22

23

24

25

26

27

28

29

30

31

32

33

34

35

36

37

38

39

40

41

42

43

44

45

46

47

48

49

50

51

52

53

54

55

56

57

58

59

60

the proposed HAR specification can significantly improve the stock index volatility forecasting performance. We have no reason to doubt that similar improvements can also be realizable for other liquid stock indices. However, further investigation is necessary into the performance of the proposed specification in key financial applications like risk management, but also for capital allocation, derivatives pricing and hedging and for other asset classes, such as bonds and currencies. 


\section{References}

Andersen, T.G. and Bollerslev, T. (1998) Answering the sceptics: yes, standard volatility models do provide accurate forecasts. International Economic Review, 39, $885-905$.

Andersen, T.G. Bollerslev, T., Diebold, F.X. and Ebens, H. (2001a) The distribution of realized stock returns volatility, Journal of Financial Economics, 6, 43-76.

Andersen, T.G., Bollerslev, T., Diebold, F.X. and Labys, P. (2001b) The distribution of realized exchange rate volatility, Journal of the American Statistical Association, 96, 42-55.

Andersen, T.G., Bollerslev, T., Diebold, F.X. and Labys, P. (2003) Modelling and forecasting realized volatility, Econometrica, 71, 579-625.

Andersen, T.G., Bollerslev, T. and Diebold, F.X. (2007) Roughing it up: Including Jump components in the measurement, modelling and forecasting of return volatility, The Review of Economics and Statistics, 89, 701-720.

Angelidis, T. and Degiannakis, S. (2008) Volatility forecasting: Intra-day versus Interday models, Journal of International Financial Markets, Institutions and Money, 18, 449-465.

Baillie, R.T., Bollerslev, T. and Mikkelsen, H.O. (1996) Fractionally integrated generalized autoregressive conditional heteroskedasticity, Journal of Econometrics, 74, 3-30.

Barndorff-Nielsen, O.E. and Shephard, N. (2004) Power and bipower variation with stochastic volatility and jumps, Journal of Financial Econometrics, 2, 1-37.

Beltratti, A. and Morana, C. (2005) Statistical Benefits of Value-at-risk with long memory, Journal of Risk, 7, 21-45. 
Bollerslev, T., Engle, R.F. and Nelson, DB. (1994) ARCH models. Handbook of Econometrics, Vol IV, 2959 - 3038.

Bollerslev, T. and Ghysels, E. (1996) Periodic Autoregressive Conditional Heteroskedasticity, Journal of Business and Economic Statistics, 14, 139-151.

Clements, M., Galvao, A. and Kim, J. (2008) Quantile forecasts of daily exchange rate returns from forecasts of realized volatility, Journal of Empirical Finance, 15, 729750.

Corsi, F. (2009) A simple approximate long memory model of realized volatility. Journal of Financial Econometrics, 7, 174-196.

Corsi, F. and Reno, R. (2009) HAR volatility modelling with heterogeneous leverage and jumps. Working Paper.

Corsi, F., Mittnik, S., Pigorsch, C. and Pigorsch, U. (2008) The volatility of realized volatility, Econometric Reviews, 27, 46-78.

Degiannakis, S. (2008) ARFIMAX and ARFIMAX-TARCH realized volatility modelling, Journal of Applied Statistics, 35,1169-1180.

Engle, R.F. and Patton, A.J. (2001) What good is a volatility model? Quantitative Finance, 1, 237-245.

Forsberg, L. and Ghysels, E. (2007) Why do absolute returns predict volatility so well?, Journal of Financial Econometrics, 5, 31-67.

Fuertes, A.M., Izzeldin, M. and Kalotychou, E. (2009) On forecasting daily stock volatility: The role of intraday information and market conditions, International Journal of Forecasting, 25, 259-281.

Ghysels, E. and Sinko, A. 2006. Comment on Hansen and Lunde JBES paper, Journal of Business and Economic Forecasting, 26,192-194. 
Ghysels, E., Santa-Clara, P. and Valkanov, R. (2006) Predicting volatility: how to get most out of returns data sampled at different frequencies, Journal of Econometrics, 131, 59-95.

Giot, P. and Laurent, S. (2004) Modelling daily value-at-risk using realized volatility and ARCH type models, Journal of Empirical Finance, 11, 379- 398.

Granger, C. (1980) Long memory relationships and the aggregation of dynamic models, Journal of Econometrics, 14, 227-238.

Granger, C. and Joyeux, R. (1980) An introduction to the long memory time series models and fractional differencing, Journal of Time Series Analysis, 1,15-29.

Hansen, P.R. (2005) A test for superior predictive ability, Journal of Business and Economic Statistics, 23, 365-380.

Hooper, V.J., Reeves, J.J. and Xie, X. (2009) Optimal modelling frequency for foreign exchange volatility forecasting, Applied Financial Economics, 19, 1159-1162.

Kisinbay, T., (2008) Predicting ability of asymmetric volatility models at medium-term horizons, Applied Economics, First published on: 05 September 2008.

Koopman, S.J., Jungbacker, B. and Hol, E. (2005) Forecasting daily variability of the S\&P100 stock index using historical, realised and implied volatility measurements, Journal of Empirical Finance, 12, 445-475.

Laurent, S. and Peters, J.P. (2002) G@RCH 2.2: an Ox package for estimating and forecasting various ARCH models, Journal of Economic Surveys, 16, 447- 484.

Liu, C. and Maheu, J.M. (2009) Forecasting realized volatility: A Bayesian modelaveraging approach, Journal of Applied Econometrics, 24, 709-733.

Marcucci, J. (2005) Forecasting stock market volatility with regime-switching GARCH models, Studies in Nonlinear dynamics and Econometrics, 9. 
Martens, M. (2002) Measuring and forecasting S\&P 500 index-futures volatility using high-frequency data, Journal of Futures Markets, 22, 497-518.

Martens, M., Dijk, D. and Pooter, M. (2009) Forecasting S\&P 500 volatility: Long memory, level shifts, leverage effects, day of the week seasonality and macroeconomic announcements, International Journal of forecasting, 25, 282-303.

McAller, M. and Medeiros, M. (2008) Realized volatility: A review, Econometric Reviews, 27, 10-45.

McMillan, D.G. and Speight, A.E. (2006a) Volatility dynamics and heterogeneous markets, International Journal of Finance and Economics, 11, 115-121.

McMillan, D.G. and Speight, A.E. (2006b) Market trader heterogeneity and high frequency volatility dynamics: further evidence from intra-day FTSE-100 futures data, Applied Financial Economics Letters, 2, 99-103.

Muller, U.A., Dacorogna, M.M., Davi, R.D., Olsen, R.B., Pictet, O.V. and von Weizsacker, J.E. (1997) Volatilities of different time resolutions - analysing the dynamics of market components, Journal of Empirical Finance, 4, 213-239.

Muller, U., Dacorogna, M., Dav, R., Pictet, O., Olsen, R. and Ward, J. (1993) Fractals and intrinsic time - A challenge to econometricians, 39th International AEA Conference on Real Time Econometrics, 14-15 October 1993, Luxembourg.

Noh, J. and Kim, T-H., (2006) Forecasting volatility of futures market: the S\&P 500 and the FTSE 100 futures using high frequency returns and implied volatility, Applied Economics, 38, 395-413.

Pagan, A.R. and Schwert, W. (1990) Alternative Models for Conditional Stock Volatility, Journal of Econometrics, 50, 267-290. 
Patton, A. (2006) Volatility forecast comparison using imperfect volatility proxies, Working paper 175, Quantitative Finance Research Centre, University of Technology, Sydney.

Politis, D.N. and Romano, J.P. (1994) The stationary bootstrap, Journal of the American Statistical Association, 89, 1303-1313.

Pong, S., Shackleton, M.B., Taylor, S.J. and Xu, X. (2004) Forecasting currency volatility: A comparison of implied volatilities and AR(FI)MA models, Journal of Banking and Finance, 28, 2541-2563.

Poon, S.H. and Granger, C.W.J. (2003) Forecasting volatility in financial markets: A review, Journal of Economic Literature, 41, 478-539.

Shimotsu, K. and Phillips, P.C.B. (2005) Exact local whittle estimation of fractional integration, The Annals of Statistics, 33, 1890-1933.

Thomakos, D. and Wang, T. (2003) Realized volatility in the futures markets, Journal of Empirical Finance, 10, 321-353.

Zhang, L., Mykland, P. and Ait-Sahalia, Y. (2005) A tale of two time scales: determining integrated volatility with noisy high frequency data, Journal of the American Statistical Association, 100, 1394-1411. 
Table 1: Descriptive statistics and stylized facts for the S\&P 500 and DJIA indices

\begin{tabular}{|c|c|c|c|c|c|c|c|c|}
\hline & \multicolumn{4}{|c|}{ S\&P 500} & \multicolumn{4}{|c|}{ DJIA } \\
\hline & $r_{t}$ & $r_{t} / \sigma_{R V, t}$ & $\sigma_{R V, t}^{2}$ & $\log \left(\sigma_{R V, t}^{2}\right)$ & $r_{t}$ & $r_{t} / \sigma_{R V, t}$ & $\sigma_{R V, t}^{2}$ & $\log \left(\sigma_{R V, t}^{2}\right)$ \\
\hline Mean & 0.0261 & 0.0882 & 0.9718 & -0.433 & 0.0263 & 0.0742 & 1.0537 & -0.3416 \\
\hline Median & 0.0492 & 0.0835 & 0.6224 & -0.4741 & 0.0336 & 0.0458 & 0.6888 & -0.3728 \\
\hline Maximum & 5.308 & 3.5254 & 13.2346 & 2.5828 & 6.2002 & 3.0564 & 17.6652 & 2.8716 \\
\hline Minimum & -7.1127 & -3.208 & 0.0543 & -2.9133 & -7.439 & -3.0309 & 0.0555 & -2.8915 \\
\hline Std. Dev. & 1.1459 & 1.1499 & 1.1658 & 0.8648 & 1.1075 & 1.0608 & 1.2942 & 0.8443 \\
\hline Skewness & -0.0777 & 0.0977 & 4.4241 & 0.277 & -0.1945 & 0.0789 & 4.6922 & 0.3079 \\
\hline \multirow[t]{2}{*}{ Kurtosis } & 6.015 & 2.5655 & 32.235 & 3.0848 & 7.0752 & 2.608 & 35.5938 & 3.3817 \\
\hline & \multicolumn{8}{|c|}{ Normality tests } \\
\hline $\begin{array}{l}\text { Jarque- } \\
\text { Bera }\end{array}$ & 952 & 24 & 97,496 & 33 & 1751 & 19 & 120,219 & 55 \\
\hline [p-value] & {$[0.0000]$} & {$[0.0000]$} & {$[0.0000]$} & {$[0.0000]$} & {$[0.0000]$} & {$[0.0001]$} & {$[0.0000]$} & {$[0.0000]$} \\
\hline Lilliefors & 0.0493 & 0.0176 & 0.2189 & 0.0213 & 0.0517 & 0.0153 & 0.2264 & 0.0299 \\
\hline [p-value] & {$[0.0000]$} & {$[0.0697]$} & {$[0.0000]$} & {$[0.0106]$} & {$[0.0000]$} & {$[>0.1]$} & {$[0.0000]$} & [0.0000] \\
\hline $\begin{array}{l}\text { Anderson- } \\
\text { Darling }\end{array}$ & 14.5295 & 1.7548 & 256.8931 & 2.3783 & 15.0759 & 1.4858 & 269.2609 & 3.2387 \\
\hline [p-value] & {$[0.0000]$} & {$[0.0002]$} & {$[0.0000]$} & {$[0.0000]$} & {$[0.0000]$} & [0.0008] & {$[0.0000]$} & {$[0.0000]$} \\
\hline
\end{tabular}


Table 2: The HAR based realized volatility models estimation results for the S\&P 500 index

\begin{tabular}{|c|c|c|c|c|c|c|}
\hline & $H A R$ & $\begin{array}{c}H A R- \\
G A R C H\end{array}$ & $A d H A R$ & AHAR & $\begin{array}{l}\text { AHAR- } \\
\text { GARCH }\end{array}$ & $\begin{array}{c}\text { AHAR- } \\
\text { FIGARCH }\end{array}$ \\
\hline \multirow{2}{*}{$a_{0}$} & -0.006 & -0.008 & $-0.074 *$ & $-0.174^{*}$ & $-0.177^{*}$ & $-0.178^{*}$ \\
\hline & $(0.013)$ & $(0.013)$ & $(0.022)$ & $(0.032)$ & $(0.031)$ & $(0.031)$ \\
\hline \multirow{2}{*}{$a_{(d)}$} & $0.301^{*}$ & $0.293^{*}$ & $0.213^{*}$ & $0.140^{*}$ & $0.139 *$ & $0.144^{*}$ \\
\hline & $(0.030)$ & $(0.035)$ & $(0.032)$ & $(0.032)$ & $(0.031)$ & $(0.032)$ \\
\hline \multirow{2}{*}{$a_{(w)}$} & $0.422 *$ & $0.454^{*}$ & $0.507^{*}$ & $0.363^{*}$ & $0.381^{*}$ & $0.375^{*}$ \\
\hline & $(0.050)$ & $(0.052)$ & $(0.050)$ & $(0.053)$ & $(0.053)$ & $(0.052)$ \\
\hline \multirow{2}{*}{$a_{(m)}$} & $0.170 *$ & $0.146^{*}$ & $0.171^{*}$ & $0.352 *$ & $0.344^{*}$ & $0.345^{*}$ \\
\hline & $(0.044)$ & $(0.044)$ & $(0.042)$ & $(0.046)$ & $(0.045)$ & $(0.045)$ \\
\hline \multirow{2}{*}{$\vartheta_{(d)}$} & --- & --- & $-0.137^{*}$ & $-0.089^{*}$ & $-0.083^{*}$ & $-0.083^{*}$ \\
\hline & & & $(0.011)$ & $(0.012)$ & $(0.012)$ & $(0.012)$ \\
\hline \multirow{2}{*}{$\vartheta_{(w)}$} & --- & --- & --- & $-0.106^{*}$ & $-0.104^{*}$ & $-0.103 *$ \\
\hline & & & & $(0.015)$ & $(0.015)$ & $(0.015)$ \\
\hline \multirow{2}{*}{$\vartheta_{(m)}$} & -- & --- & --- & $-0.056^{*}$ & $-0.057 *$ & $-0.058 *$ \\
\hline & & & & $(0.016)$ & $(0.016)$ & $(0.015)$ \\
\hline \multirow{2}{*}{$\gamma_{(d)}$} & --- & --- & $0.081 *$ & $0.060 *$ & $0.059 *$ & $0.059^{*}$ \\
\hline & & & $(0.020)$ & (0.019) & $(0.019)$ & $(0.018)$ \\
\hline \multirow{2}{*}{$\gamma_{(w)}$} & --- & --- & --- & $0.055^{*}$ & $0.055^{*}$ & $0.055^{*}$ \\
\hline & & & & $(0.020)$ & $(0.020)$ & $(0.020)$ \\
\hline \multirow{2}{*}{$\gamma_{(m)}$} & --- & --- & --- & $0.092 *$ & $0.096^{*}$ & $0.096^{*}$ \\
\hline & & & & $(0.022)$ & $(0.022)$ & $(0.021)$ \\
\hline \multirow{2}{*}{$\omega$} & $0.280 *$ & 0.030 & $0.255^{*}$ & $0.240^{*}$ & 0.005 & 0.017 \\
\hline & $(0.010)$ & $(0.023)$ & $(0.010)$ & $(0.010)$ & $(0.004)$ & $(0.010)$ \\
\hline \multirow{2}{*}{$d_{u}$} & --- & --- & --- & --- & --- & $0.222 *$ \\
\hline & & & & & & $(0.077)$ \\
\hline \multirow{2}{*}{$\alpha_{1}$} & --- & $0.057 * *$ & --- & --- & $0.021 * *$ & --- \\
\hline & & $(0.025)$ & & & $(0.009)$ & \\
\hline \multirow{2}{*}{$\beta_{1}$} & --- & $0.832 *$ & -- & --- & $0.955^{*}$ & $0.736^{*}$ \\
\hline & & $(0.104)$ & & & $(0.022)$ & $(0.070)$ \\
\hline \multirow[b]{2}{*}{$\varphi_{1}$} & --- & --- & --- & --- & --- & $0.570 *$ \\
\hline & & & & & & $(0.085)$ \\
\hline $\log L$ & $-1,163$ & $-1,153$ & $-1,095$ & $-1,049$ & $-1,042$ & $-1,040$ \\
\hline$A I C$ & 1.573 & 1.563 & 1.483 & 1.427 & 1.420 & 1.419 \\
\hline SIC & 1.591 & 1.588 & 1.508 & 1.466 & 1.467 & 1.469 \\
\hline Skewness & 0.333 & 0.309 & 0.307 & 0.308 & 0.306 & 0.294 \\
\hline Excess Kurt. & 0.529 & 0.559 & 0.610 & 0.766 & 0.828 & 0.784 \\
\hline$I R$ & 45 & 43 & 51 & 59 & 65 & 59 \\
\hline$J B$ & {$[0.000]$} & {$[0.000]$} & {$[0.000]$} & {$[0.000]$} & {$[0.000]$} & {$[0.000]$} \\
\hline$Q(5)$ & {$[0.560]$} & {$[0.657]$} & {$[0.095]$} & {$[0.748]$} & [0.829] & {$[0.837]$} \\
\hline$Q(50)$ & {$[0.244]$} & {$[0.277]$} & [0.182] & {$[0.424]$} & [0.229] & {$[0.507]$} \\
\hline$Q^{2}(5)$ & {$[0.001]$} & {$[0.259]$} & {$[0.031]$} & [0.319] & {$[0.392]$} & {$[0.794]$} \\
\hline$Q^{2}(50)$ & [0.212] & {$[0.800]$} & {$[0.657]$} & {$[0.860]$} & {$[0.976]$} & {$[0.978]$} \\
\hline$A R C H-L M(2)$ & [0.0007] & [0.4438] & {$[0.005]$} & [0.098] & [0.257] & [0.800] \\
\hline$A R C H-L M(5)$ & {$[0.0055]$} & [0.6079] & {$[0.057]$} & {$[0.416]$} & {$[0.752]$} & {$[0.961]$} \\
\hline
\end{tabular}


Table 3: The HAR based realized volatility models estimation results for the DJIA index

\begin{tabular}{|c|c|c|c|c|c|c|}
\hline & $H A R$ & $\begin{array}{c}\text { HAR- } \\
\text { GARCH }\end{array}$ & $A d H A R$ & AHAR & $\begin{array}{l}\text { AHAR- } \\
\text { GARCH }\end{array}$ & $\begin{array}{c}\text { AHAR- } \\
\text { FIGARCH }\end{array}$ \\
\hline$a_{0}$ & $\begin{array}{c}0.002 \\
(0.013)\end{array}$ & $\begin{array}{c}-0.006 \\
(0.013)\end{array}$ & $\begin{array}{l}-0.070^{*} \\
(0.022)\end{array}$ & $\begin{array}{l}-0.168^{*} \\
(0.031)\end{array}$ & $\begin{array}{l}-0.168^{*} \\
(0.030)\end{array}$ & $\begin{array}{l}-0.170^{*} \\
(0.030)\end{array}$ \\
\hline & $0.291^{*}$ & $0.291^{*}$ & $0.224^{*}$ & $0.167^{*}$ & $0.170^{*}$ & $0.169^{*}$ \\
\hline$u_{(d)}$ & $(0.030)$ & $(0.034)$ & $(0.032)$ & $(0.032)$ & $(0.035)$ & $(0.032)$ \\
\hline$a_{(w)}$ & $\begin{array}{l}0.450^{*} \\
(0.050)\end{array}$ & $\begin{array}{c}0.450^{*} \\
(0.053)\end{array}$ & $\begin{array}{l}0.510^{*} \\
(0.051)\end{array}$ & $\begin{array}{l}0.389^{*} \\
(0.054)\end{array}$ & $\begin{array}{l}0.400^{*} \\
(0.056)\end{array}$ & $\begin{array}{l}0.403^{*} \\
(0.053)\end{array}$ \\
\hline$a_{(m)}$ & $\begin{array}{l}0.144^{*} \\
(0.044)\end{array}$ & $\begin{array}{l}0.146^{*} \\
(0.044)\end{array}$ & $\begin{array}{l}0.154^{*} \\
(0.044)\end{array}$ & $\begin{array}{l}0.301^{*} \\
(0.045)\end{array}$ & $\begin{array}{l}0.291^{*} \\
(0.045)\end{array}$ & $\begin{array}{l}0.291 * \\
(0.046)\end{array}$ \\
\hline$\vartheta_{(d)}$ & -- & --- & $\begin{array}{l}-0.114^{*} \\
(0.012)\end{array}$ & $\begin{array}{l}-0.073^{*} \\
(0.013)\end{array}$ & $\begin{array}{l}-0.070^{*} \\
(0.013)\end{array}$ & $\begin{array}{c}-0.070^{*} \\
(0.013)\end{array}$ \\
\hline$\vartheta_{(w)}$ & --- & --- & --- & $\begin{array}{l}-0.092^{*} \\
(0.015)\end{array}$ & $\begin{array}{l}-0.088^{*} \\
(0.016)\end{array}$ & $\begin{array}{l}-0.089^{*} \\
(0.016)\end{array}$ \\
\hline$\vartheta_{(m)}$ & -- & --- & --- & $\begin{array}{l}-0.050^{*} \\
(0.016)\end{array}$ & $\begin{array}{l}-0.050^{*} \\
(0.016)\end{array}$ & $\begin{array}{c}-0.050^{*} \\
(0.016)\end{array}$ \\
\hline$\gamma_{(d)}$ & --- & --- & $\begin{array}{l}0.091 * \\
(0.021)\end{array}$ & $\begin{array}{l}0.067^{*} \\
(0.020)\end{array}$ & $\begin{array}{c}0.067^{*} \\
(0.020)\end{array}$ & $\begin{array}{l}0.067^{*} \\
(0.020)\end{array}$ \\
\hline$\gamma_{(w)}$ & - & --- & --- & $\begin{array}{l}0.068^{*} \\
(0.021)\end{array}$ & $\begin{array}{c}0.065^{*} \\
(0.021)\end{array}$ & $\begin{array}{l}0.066^{*} \\
(0.021)\end{array}$ \\
\hline$\gamma_{(m)}$ & --- & -- & --- & $\begin{array}{l}0.089^{*} \\
(0.022)\end{array}$ & $\begin{array}{l}0.087^{*} \\
(0.022)\end{array}$ & $\begin{array}{l}0.088^{*} \\
(0.022)\end{array}$ \\
\hline$\omega$ & $\begin{array}{l}0.265^{*} \\
(0.009)\end{array}$ & $\begin{array}{c}0.086^{* *} \\
(0.042)\end{array}$ & $\begin{array}{c}0.249^{*} \\
0.010\end{array}$ & $\begin{array}{l}0.237^{*} \\
(0.010)\end{array}$ & $\begin{array}{c}0.078 \\
(0.074)\end{array}$ & $\begin{array}{l}0.162^{*} \\
(0.029)\end{array}$ \\
\hline$d_{u}$ & --- & -- & --- & --- & --- & $\begin{array}{c}0.050^{* *} \\
(0.024)\end{array}$ \\
\hline$\alpha_{1}$ & --- & $\begin{array}{c}0.087^{*} \\
(0.031)\end{array}$ & --- & --- & $\begin{array}{c}0.046 \\
(0.038)\end{array}$ & --- \\
\hline$\beta_{1}$ & --- & $\begin{array}{c}0.585^{*} \\
(0.178)\end{array}$ & --- & --- & $\begin{array}{c}0.621 \\
(0.331)\end{array}$ & --- \\
\hline$\varphi_{1}$ & --- & --- & --- & --- & --- & --- \\
\hline $\log L$ & $-1,121$ & $-1,113$ & $-1,076$ & $-1,040$ & $-1,037$ & $-1,037$ \\
\hline$A I C$ & 1.517 & 1.508 & 1.458 & 1.414 & 1.414 & 1.412 \\
\hline SIC & 1.535 & 1.533 & 1.483 & 1.454 & 1.460 & 1.455 \\
\hline Skewness & 0.300 & 0.265 & 0.254 & 0.236 & 0.237 & 0.244 \\
\hline Excess Kurt. & 0.767 & 0.653 & 0.796 & 1.019 & 0.921 & 0.911 \\
\hline$J B$ & $\begin{array}{c}58 \\
{[0.000]}\end{array}$ & $\begin{array}{c}43 \\
{[0.000]}\end{array}$ & $\begin{array}{c}55 \\
{[0.000]}\end{array}$ & $\begin{array}{c}78 \\
{[0.000]}\end{array}$ & {$[0.000]$} & $\begin{array}{c}66 \\
{[0.000]}\end{array}$ \\
\hline$Q(5)$ & {$[0.255]$} & {$[0.422]$} & {$[0.136]$} & {$[0.651]$} & {$[0.715]$} & {$[0.721]$} \\
\hline$Q(50)$ & {$[0.074]$} & {$[0.078]$} & {$[0.049]$} & {$[0.051]$} & {$[0.050]$} & {$[0.056]$} \\
\hline$Q^{2}(5)$ & {$[0.005]$} & {$[0.207]$} & {$[0.088]$} & {$[0.534]$} & {$[0.669]$} & {$[0.953]$} \\
\hline$Q^{2}(50)$ & {$[0.201]$} & [0.639] & {$[0.035]$} & {$[0.512]$} & {$[0.631]$} & {$[0.781]$} \\
\hline$A R C H-L M(2)$ & {$[0.005]$} & {$[0.832]$} & {$[0.057]$} & {$[0.342]$} & {$[0.632]$} & {$[0.724]$} \\
\hline$A R C H-L M(5)$ & {$[0.009]$} & {$[0.485]$} & {$[0.131]$} & {$[0.556]$} & {$[0.908]$} & {$[0.953]$} \\
\hline \multicolumn{7}{|c|}{$\begin{array}{l}\text { Notes: Standard errors are presented in parentheses. * and } * * \text { indicate statistical significance at } 1 \% \text {, and } 5 \% \\
\text { significance levels respectively. } \log L \text { is the optimized value of the log likelihood. A(S)IC is the Akaike } \\
\text { (Schwartz) Information Criterion. } Q(h) \text { and } Q^{2}(h) \text { are the Ljung-Box statistics for } \mathrm{h}^{\text {th }} \text { order serial } \\
\text { correlation for the standardized and squared standardized residuals respectively. The } p \text {-values for the } \\
\text { Jarque Bera (JB), } Q(), Q^{2}(\cdot) \text { and the } A L C H-L M() \text { test statistics are depicted in brackets. }\end{array}$} \\
\hline
\end{tabular}


Table 4: The ARFIMA realized volatility models estimation results for the S\&P 500 and DJIA indices

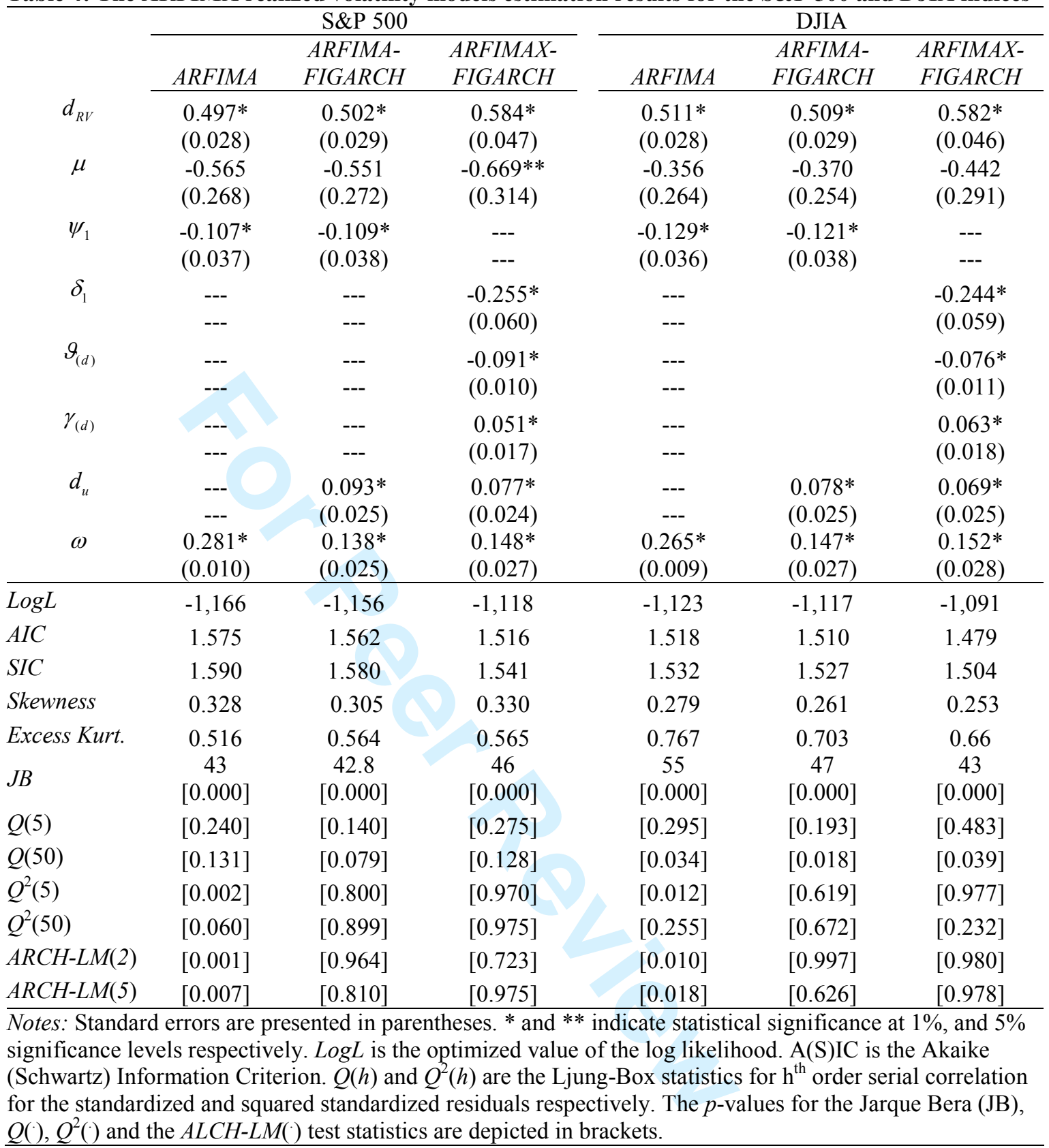




$$
\begin{aligned}
& M S E=(1 / n) \sum_{t=1}^{n}\left(\sigma_{R V, t}-\hat{\sigma}_{R V, t / t-1}^{j}\right)^{2} \\
& M A E=(1 / n) \sum_{t=1}^{n}\left|\sigma_{R V, t}-\hat{\sigma}_{R V, t / t-1}^{j}\right| \\
& M A P E=(1 / n) \sum_{t=1}^{n}\left(\left|\sigma_{R V, t}-\hat{\sigma}_{R V, t / t-1}^{j}\right| / \sigma_{R V, t}\right) \\
& M L A E=(1 / n) \sum_{t=1}^{n}\left(\log \left|\sigma_{R V, t}-\hat{\sigma}_{R V, t / t-1}^{j}\right|\right) \\
& \text { QLIKE }=(1 / n) \sum_{t=1}^{n}\left(\log \left(\hat{\sigma}_{R V, t / t-1}^{j}\right)+\sigma_{R V, t} / \hat{\sigma}_{R V, t / t-1}^{j}\right) \\
& R 2 L O G=(1 / n) \sum_{t=1}^{n}\left(\log \left(\sigma_{R V, t} / \hat{\sigma}_{R V, t / t-1}^{j}\right)\right)^{2} \\
& H M S E=(1 / n) \sum_{t=1}^{n}\left(\left(\sigma_{R V, t} / \hat{\sigma}_{R V, t / t-1}^{j}\right)-1\right)^{2}
\end{aligned}
$$


Table 6: Forecast loss functions for the S\&P 500 index

\begin{tabular}{|c|c|c|c|c|c|c|c|}
\hline & \multicolumn{7}{|c|}{1 day ahead } \\
\hline & MSE & MAE & MAPE & MALE & QLIKE & R2LOG & HMSE \\
\hline HAR & $0.02754(11)$ & $0.13093(11)$ & $0.22473(11)$ & $-2.44812(10)$ & $0.54104(10)$ & $0.06521(11)$ & $0.05721(9)$ \\
\hline HAR-GARCH & $0.02698(8)$ & $0.12915(9)$ & $0.22145(10)$ & $-2.47833(9)$ & $0.54056(8)$ & $0.06400(9)$ & $0.05664(7)$ \\
\hline $\mathrm{A} d \mathrm{HAR}$ & $0.02567(6)$ & $0.12470(6)$ & $0.21038(6)$ & $-2.49526(7)$ & $0.53752(5)$ & $0.05749(6)$ & $0.05047(6)$ \\
\hline AHAR & $0.02471(5)$ & $0.12124(5)$ & $0.20292(5)$ & $-2.53066(5)$ & $0.53625(4)$ & $0.05446(5)$ & $0.04885(1)$ \\
\hline AHAR-GARCH & $0.02436(4)$ & $0.12035(4)$ & $0.20129(4)$ & $-2.53859(4)$ & $0.53611(3)$ & $0.05397(4)$ & $0.04897(4)$ \\
\hline AHAR-FIGARCH & $0.02429(3)$ & $0.12011(3)$ & $0.20081(3)$ & $-2.55167(2)$ & $0.53608(2)$ & $0.05387(3)$ & $0.04903(5)$ \\
\hline AHAR-RPV-GARCH & $0.02422(2)$ & $0.12000(2)$ & $0.20053(2)$ & $-2.54340(3)$ & $0.53599(1)$ & $0.05366(2)$ & $0.04886(2)$ \\
\hline AHAR-RPV-FIGARCH & $0.02418(1)$ & $0.11979(1)$ & $0.20016(1)$ & $-2.55954(1)$ & $0.53599(1)$ & $0.05362(1)$ & $0.04895(3)$ \\
\hline ARFIMA & $0.02741(10)$ & $0.13019(10)$ & $0.22192(9)$ & $-2.44282(11)$ & $0.54080(9)$ & $0.06428(10)$ & $0.05765(11)$ \\
\hline ARFIMA-FIGARCH & $0.02679(7)$ & $0.12813(8)$ & $0.21818(8)$ & $-2.48507(8)$ & $0.54030(7)$ & $0.06302(8)$ & $0.05712(8)$ \\
\hline \multirow[t]{3}{*}{ ARFIMAX-FIGARCH } & $0.02710(9)$ & $0.12676(7)$ & $0.21337(7)$ & $-2.50304(6)$ & $0.53999(6)$ & $0.06179(7)$ & $0.05761(10)$ \\
\hline & \multicolumn{5}{|c|}{5 days ahead } & & \\
\hline & MSE & MAE & MAPE & MALE & QLIKE & R2LOG & HMSE \\
\hline HAR & $0.07903(11)$ & $0.22149(11)$ & $0.15750(11)$ & $-1.92672(11)$ & $1.36566(11)$ & $0.03447(11)$ & $0.03276(11)$ \\
\hline HAR-GARCH & $0.07678(10)$ & $0.21836(10)$ & $0.15511(10)$ & $-1.93484(10)$ & $1.36525(10)$ & $0.03360(10)$ & $0.03198(9)$ \\
\hline $\mathrm{A} d \mathrm{HAR}$ & $0.06925(6)$ & $0.20407(6)$ & $0.14334(6)$ & $-2.03282(6)$ & $1.36317(6)$ & $0.02922(6)$ & $0.02798(6)$ \\
\hline AHAR & $0.06815(5)$ & $0.19887(5)$ & $0.13702(5)$ & $-2.08784(5)$ & $1.36222(5)$ & $0.02720(5)$ & $0.02624(5)$ \\
\hline AHAR-GARCH & $0.06629(4)$ & $0.19707(4)$ & $0.13570(4)$ & $-2.10483(2)$ & $1.36204(4)$ & $0.02673(4)$ & $0.02604(2)$ \\
\hline AHAR-FIGARCH & $0.06598(3)$ & $0.19666(3)$ & $0.13536(3)$ & $-2.10584(1)$ & $1.36202(3)$ & $0.02667(3)$ & $0.02607(4)$ \\
\hline AHAR-RPV-GARCH & $0.06589(2)$ & $0.19658(2)$ & $0.13529(2)$ & $-2.09471(3)$ & $1.36200(2)$ & $0.02660(2)$ & $0.02605(3)$ \\
\hline AHAR-RPV-FIGARCH & $0.06549(1)$ & $0.19608(1)$ & $0.13492(1)$ & $-2.09350(4)$ & $1.36197(1)$ & $0.02651(1)$ & $0.02603(1)$ \\
\hline ARFIMA & $0.07558(9)$ & $0.21737(9)$ & $0.15370(9)$ & $-1.96463(8)$ & $1.36513(9)$ & $0.03309(9)$ & $0.03240(10)$ \\
\hline ARFIMA-FIGARCH & $0.07301(8)$ & $0.21339(8)$ & $0.15086(8)$ & $-1.96396(9)$ & $1.36472(8)$ & $0.03219(8)$ & $0.03163(8)$ \\
\hline \multirow[t]{3}{*}{ ARFIMAX-FIGARCH } & $0.07260(7)$ & $0.21084(7)$ & $0.14761(7)$ & $-1.98752(7)$ & $1.36433(7)$ & $0.03125(7)$ & $0.03108(7)$ \\
\hline & \multicolumn{7}{|c|}{22 days ahead } \\
\hline & MSE & MAE & MAPE & MALE & QLIKE & R2LOG & HMSE \\
\hline HAR & $0.36614(11)$ & $0.46121(11)$ & $0.15018(11)$ & $-1.26200(9)$ & $2.12040(11)$ & $0.03282(11)$ & $0.03122(10)$ \\
\hline HAR-GARCH & $0.35599(10)$ & $0.45441(9)$ & $0.14793(10)$ & $-1.26179(8)$ & $2.12003(9)$ & $0.03204(10)$ & $0.03046(8)$ \\
\hline $\mathrm{A} d \mathrm{HAR}$ & $0.35048(8)$ & $0.44981(8)$ & $0.14572(8)$ & $-1.27375(7)$ & $2.11969(7)$ & $0.03115(8)$ & $0.03015(6)$ \\
\hline AHAR & $0.34198(7)$ & $0.43575(5)$ & $0.14064(5)$ & $-1.33178(1)$ & $2.11905(5)$ & $0.02995(5)$ & $0.02868(5)$ \\
\hline AHAR-GARCH & $0.33365(4)$ & $0.43166(3)$ & $0.13927(4)$ & $-1.31668(5)$ & $2.11888(2)$ & $0.02953(3)$ & $0.02849(2)$ \\
\hline AHAR-FIGARCH & $0.33209(2)$ & $0.43068(2)$ & $0.13894(2)$ & $-1.32441(2)$ & $2.11886(1)$ & $0.02947(2)$ & $0.02848(1)$ \\
\hline AHAR-RPV-GARCH & $0.33285(3)$ & $0.43173(4)$ & $0.13925(3)$ & $-1.32093(3)$ & $2.11893(4)$ & $0.02957(4)$ & $0.02872(4)$ \\
\hline AHAR-RPV-FIGARCH & $0.33087(1)$ & $0.43052(1)$ & $0.13882(1)$ & $-1.31868(4)$ & $2.11889(3)$ & $0.02946(1)$ & $0.02866(3)$ \\
\hline ARFIMA & $0.35210(9)$ & $0.45681(10)$ & $0.14790(9)$ & $-1.22333(11)$ & $2.12004(10)$ & $0.03170(9)$ & $0.03134(11)$ \\
\hline ARFIMA-FIGARCH & $0.34099(5)$ & $0.44845(7)$ & $0.14533(7)$ & $-1.24961(10)$ & $2.11970(8)$ & $0.03098(7)$ & $0.03065(9)$ \\
\hline ARFIMAX-FIGARCH & $0.34112(6)$ & $0.44562(6)$ & $0.14346(6)$ & $-1.28563(6)$ & $2.11953(6)$ & $0.03054(6)$ & $0.03042(7)$ \\
\hline
\end{tabular}


Table 7: Forecast loss functions for the DJIA index

\begin{tabular}{|c|c|c|c|c|c|c|c|}
\hline & \multicolumn{7}{|c|}{1 day ahead } \\
\hline & MSE & MAE & MAPE & MALE & QLIKE & R2LOG & HMSE \\
\hline HAR & $0.03400(10)$ & $0.14391(11)$ & $0.23456(11)$ & $-2.37560(8)$ & $0.59615(9)$ & $0.07068(11)$ & $0.06238(8)$ \\
\hline HAR-GARCH & $0.03375(9)$ & $0.14310(9)$ & $0.23303(10)$ & $-2.37477(9)$ & $0.59587(7)$ & $0.07002(10)$ & $0.06197(7)$ \\
\hline $\mathrm{A} d \mathrm{HAR}$ & $0.03229(5)$ & $0.13783(6)$ & $0.22141(6)$ & $-2.41244(6)$ & $0.59306(4)$ & $0.06393(6)$ & $0.05646(6)$ \\
\hline AHAR & $0.03103(4)$ & $0.13411(5)$ & $0.21412(5)$ & $-2.43164(5)$ & $0.59171(3)$ & $0.06059(5)$ & $0.05498(1)$ \\
\hline AHAR-GARCH & $0.03088(3)$ & $0.13357(4)$ & $0.21320(4)$ & $-2.43635(3)$ & $0.59166(2)$ & $0.06039(4)$ & $0.05509(4)$ \\
\hline AHAR-FIGARCH & $0.03088(3)$ & $0.13354(3)$ & $0.21302(3)$ & $-2.43243(4)$ & $0.59166(2)$ & $0.06036(3)$ & $0.05516(5)$ \\
\hline AHAR-RPV-GARCH & $0.03060(1)$ & $0.13277(2)$ & $0.21157(2)$ & $-2.45302(2)$ & $0.59146(1)$ & $0.05980(2)$ & $0.05500(2)$ \\
\hline AHAR-RPV-FIGARCH & $0.03061(2)$ & $0.13276(1)$ & $0.21144(1)$ & $-2.45835(1)$ & $0.59146(1)$ & $0.05978(1)$ & $0.05507(3)$ \\
\hline ARFIMA & $0.03395(8)$ & $0.14331(10)$ & $0.23197(9)$ & $-2.35751(11)$ & $0.59588(8)$ & $0.06967(9)$ & $0.06289(11)$ \\
\hline ARFIMA-FIGARCH & $0.03336(6)$ & $0.14143(8)$ & $0.22761(8)$ & $-2.36889(10)$ & $0.59529(6)$ & $0.06804(8)$ & $0.06244(9)$ \\
\hline \multirow[t]{3}{*}{ ARFIMAX-FIGARCH } & $0.03338(7)$ & $0.14036(7)$ & $0.22474(7)$ & $-2.38481(7)$ & $0.59507(5)$ & $0.06717(7)$ & $0.06281(10)$ \\
\hline & \multicolumn{7}{|c|}{5 days ahead } \\
\hline & MSE & MAE & MAPE & MALE & QLIKE & R2LOG & HMSE \\
\hline HAR & $0.08536(11)$ & $0.22905(11)$ & $0.15484(11)$ & $-1.92239(9)$ & $1.42230(10)$ & $0.03360(11)$ & $0.03119(11)$ \\
\hline HAR-GARCH & $0.08487(10)$ & $0.22799(10)$ & $0.15400(10)$ & $-1.90838(11)$ & $1.42211(9)$ & $0.03325(10)$ & $0.03068(10)$ \\
\hline $\mathrm{A} d \mathrm{HAR}$ & $0.07425(6)$ & $0.21252(6)$ & $0.14220(6)$ & $-1.96637(6)$ & $1.41989(5)$ & $0.02844(6)$ & $0.02667(6)$ \\
\hline AHAR & $0.07128(5)$ & $0.20555(5)$ & $0.13502(5)$ & $-2.03602(5)$ & $1.41884(4)$ & $0.02843(5)$ & $0.02481(5)$ \\
\hline AHAR-GARCH & $0.07051(4)$ & $0.20430(4)$ & $0.13421(4)$ & $-2.04570(2)$ & $1.41873(3)$ & $0.02596(4)$ & $0.02462(3)$ \\
\hline AHAR-FIGARCH & $0.07043(3)$ & $0.20422(3)$ & $0.13408(3)$ & $-2.04446(3)$ & $1.41873(3)$ & $0.02593(3)$ & $0.02465(4)$ \\
\hline AHAR-RPV-GARCH & $0.06956(2)$ & $0.20315(2)$ & $0.13328(2)$ & $-2.04698(1)$ & $1.41863(2)$ & $0.02567(2)$ & $0.02457(1)$ \\
\hline AHAR-RPV-FIGARCH & $0.06949(1)$ & $0.20304(1)$ & $0.13314(1)$ & $-2.04294(4)$ & $1.41862(1)$ & $0.02564(1)$ & $0.02458(2)$ \\
\hline ARFIMA & $0.08172(9)$ & $0.22492(9)$ & $0.15122(9)$ & $-1.91136(10)$ & $1.42174(8)$ & $0.03221(9)$ & $0.03054(9)$ \\
\hline ARFIMA-FIGARCH & $0.08011(8)$ & $0.22157(8)$ & $0.14824(8)$ & $-1.93425(8)$ & $1.42140(7)$ & $0.03210(8)$ & $0.03010(8)$ \\
\hline \multirow[t]{3}{*}{ ARFIMAX-FIGARCH } & $0.07835(7)$ & $0.21790(7)$ & $0.14540(7)$ & $-1.94435(7)$ & $1.42095(6)$ & $0.03037(7)$ & $0.02939(7)$ \\
\hline & \multicolumn{7}{|c|}{22 days ahead } \\
\hline & MSE & MAE & MAPE & MALE & QLIKE & R2LOG & HMSE \\
\hline HAR & $0.38902(11)$ & $0.47317(11)$ & $0.14591(11)$ & $-1.24074(11)$ & $2.17779(11)$ & $0.03141(11)$ & $0.02962(11)$ \\
\hline HAR-GARCH & $0.38482(10)$ & $0.46746(10)$ & $0.14407(10)$ & $-1.26285(9)$ & $2.17750(10)$ & $0.03088(10)$ & $0.02883(8)$ \\
\hline $\mathrm{A} d \mathrm{HAR}$ & $0.35515(6)$ & $0.45124(6)$ & $0.13897(7)$ & $-1.29824(6)$ & $2.17668(6)$ & $0.02888(6)$ & $0.02792(6)$ \\
\hline AHAR & $0.34309(5)$ & $0.43626(5)$ & $0.13439(5)$ & $-1.32586(5)$ & $2.17602(5)$ & $0.02767(5)$ & $0.02628(5)$ \\
\hline AHAR-GARCH & $0.33838(3)$ & $0.43309(3)$ & $0.13333(3)$ & $-1.33379(4)$ & $2.17581(2)$ & $0.02728(3)$ & $0.02579(1)$ \\
\hline AHAR-FIGARCH & $0.33882(4)$ & $0.43344(4)$ & $0.13337(4)$ & $-1.33834(3)$ & $2.17585(4)$ & $0.02732(4)$ & $0.02591(2)$ \\
\hline AHAR-RPV-GARCH & $0.33481(1)$ & $0.43158(1)$ & $0.13277(1)$ & $-1.34850(2)$ & $2.17580(1)$ & $0.02716(1)$ & $0.02597(3)$ \\
\hline AHAR-RPV-FIGARCH & $0.33519(2)$ & $0.43182(2)$ & $0.13279(2)$ & $-1.35292(1)$ & $2.17583(3)$ & $0.02719(2)$ & $0.02608(4)$ \\
\hline ARFIMA & $0.37422(9)$ & $0.46482(9)$ & $0.14261(9)$ & $-1.24730(10)$ & $2.17738(9)$ & $0.03024(9)$ & $0.02948(10)$ \\
\hline ARFIMA-FIGARCH & $0.36799(8)$ & $0.45784(8)$ & $0.14004(8)$ & $-1.27711(8)$ & $2.17713(8)$ & $0.02968(8)$ & $0.02901(9)$ \\
\hline ARFIMAX-FIGARCH & $0.36250(7)$ & $0.45334(7)$ & $0.13848(6)$ & $-1.27851(7)$ & $2.17685(7)$ & $0.02903(7)$ & $0.02859(7)$ \\
\hline
\end{tabular}


Table 8: Forecast loss functions for the S\&P 500 and DJIA indices using the TTS estimator for the realized variance

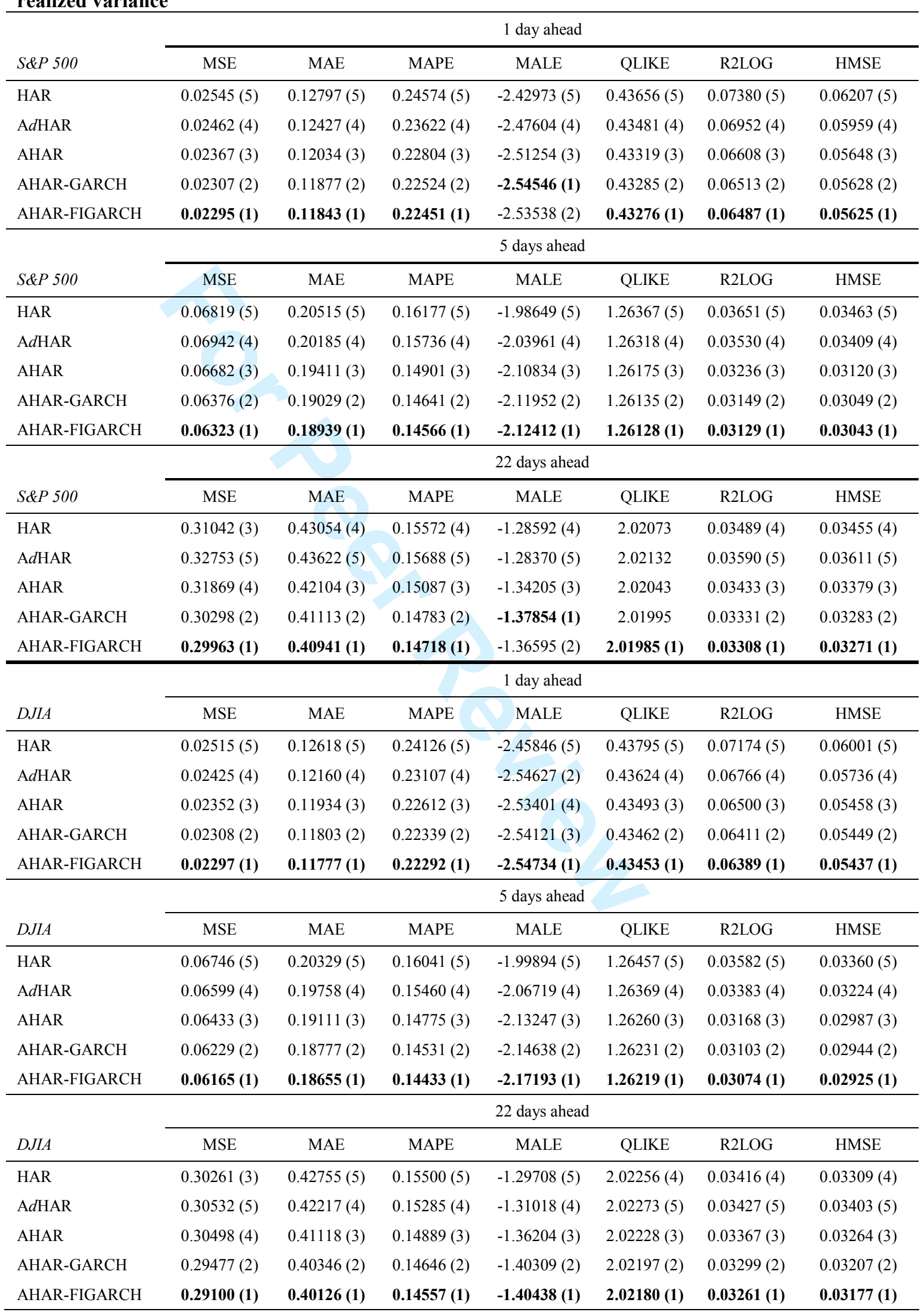


Table 9: Superior Predictive Ability (SPA) test $p$-values

\begin{tabular}{|c|c|c|c|c|c|c|}
\hline & \multicolumn{6}{|c|}{ S\&P 500} \\
\hline & \multicolumn{2}{|c|}{1 day ahead } & \multicolumn{2}{|c|}{5 days ahead } & \multicolumn{2}{|c|}{22 days ahead } \\
\hline & MSE & QLIKE & MSE & QLIKE & MSE & QLIKE \\
\hline HAR & 0.000 & 0.000 & 0.000 & 0.000 & 0.000 & 0.002 \\
\hline HAR-GARCH & 0.000 & 0.008 & 0.007 & 0.000 & 0.028 & 0.039 \\
\hline $\mathrm{A} d \mathrm{HAR}$ & 0.000 & 0.015 & 0.071 & 0.000 & 0.008 & 0.047 \\
\hline AHAR & 0.000 & 0.000 & 0.000 & 0.001 & 0.001 & 0.013 \\
\hline AHAR-GARCH & 0.001 & 0.000 & 0.010 & 0.053 & 0.086 & 0.514 \\
\hline AHAR-FIGARCH & 0.002 & 0.003 & 0.005 & 0.043 & 0.364 & 0.996 \\
\hline AHAR-RPV-GARCH & 0.071 & 0.089 & 0.206 & 0.508 & 0.033 & 0.172 \\
\hline AHAR-RPV-FIGARCH & 0.909 & 0.512 & 0.877 & 0.492 & 0.951 & 0.623 \\
\hline ARFIMA & 0.000 & 0.000 & 0.000 & 0.000 & 0.000 & 0.009 \\
\hline ARFIMA-FIGARCH & 0.014 & 0.000 & 0.052 & 0.000 & 0.549 & 0.300 \\
\hline \multirow[t]{4}{*}{ ARFIMAX-FIGARCH } & 0.005 & 0.000 & 0.130 & 0.000 & 0.595 & 0.407 \\
\hline & \multicolumn{6}{|c|}{ DJIA } \\
\hline & \multicolumn{2}{|c|}{1 day ahead } & \multicolumn{2}{|c|}{5 days ahead } & \multicolumn{2}{|c|}{22 days ahead } \\
\hline & MSE & QLIKE & MSE & QLIKE & MSE & QLIKE \\
\hline HAR & 0.005 & 0.000 & 0.000 & 0.000 & 0.007 & 0.006 \\
\hline HAR-GARCH & 0.005 & 0.000 & 0.002 & 0.000 & 0.021 & 0.010 \\
\hline $\mathrm{A} d \mathrm{HAR}$ & 0.014 & 0.000 & 0.067 & 0.000 & 0.065 & 0.023 \\
\hline AHAR & 0.000 & 0.000 & 0.001 & 0.000 & 0.004 & 0.000 \\
\hline AHAR-GARCH & 0.000 & 0.000 & 0.001 & 0.011 & 0.011 & 0.745 \\
\hline AHAR-FIGARCH & 0.000 & 0.000 & 0.001 & 0.014 & 0.003 & 0.110 \\
\hline AHAR-RPV-GARCH & 0.733 & 0.647 & 0.437 & 0.292 & 0.994 & 0.961 \\
\hline AHAR-RPV-FIGARCH & 0.291 & 0.353 & 0.932 & 0.711 & 0.518 & 0.152 \\
\hline ARFIMA & 0.000 & 0.000 & 0.008 & 0.001 & 0.038 & 0.042 \\
\hline ARFIMA-FIGARCH & 0.019 & 0.000 & 0.016 & 0.000 & 0.139 & 0.079 \\
\hline ARFIMAX-FIGARCH & 0.024 & 0.000 & 0.064 & 0.000 & 0.241 & 0.116 \\
\hline
\end{tabular}




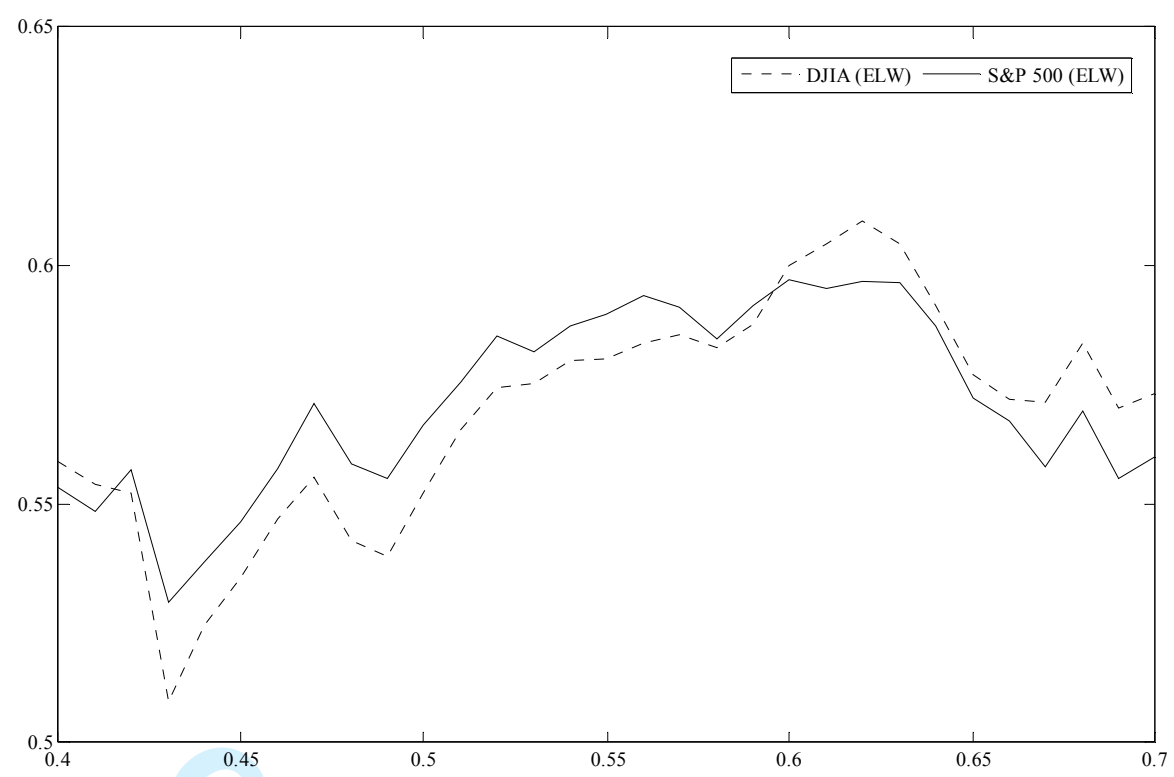

Fig. 1. S\&P 500 and DJIA indices log realized variance ELW fractional differencing parameter estimates

Editorial Office, Dept of Economics, Warwick U1 University, Coventry CV4 7AL, UK 
Fig. 2. The impact on volatility from lagged negative and positive daily, weekly and monthly standardized returns for the S\&P 500 and DJIA indices 


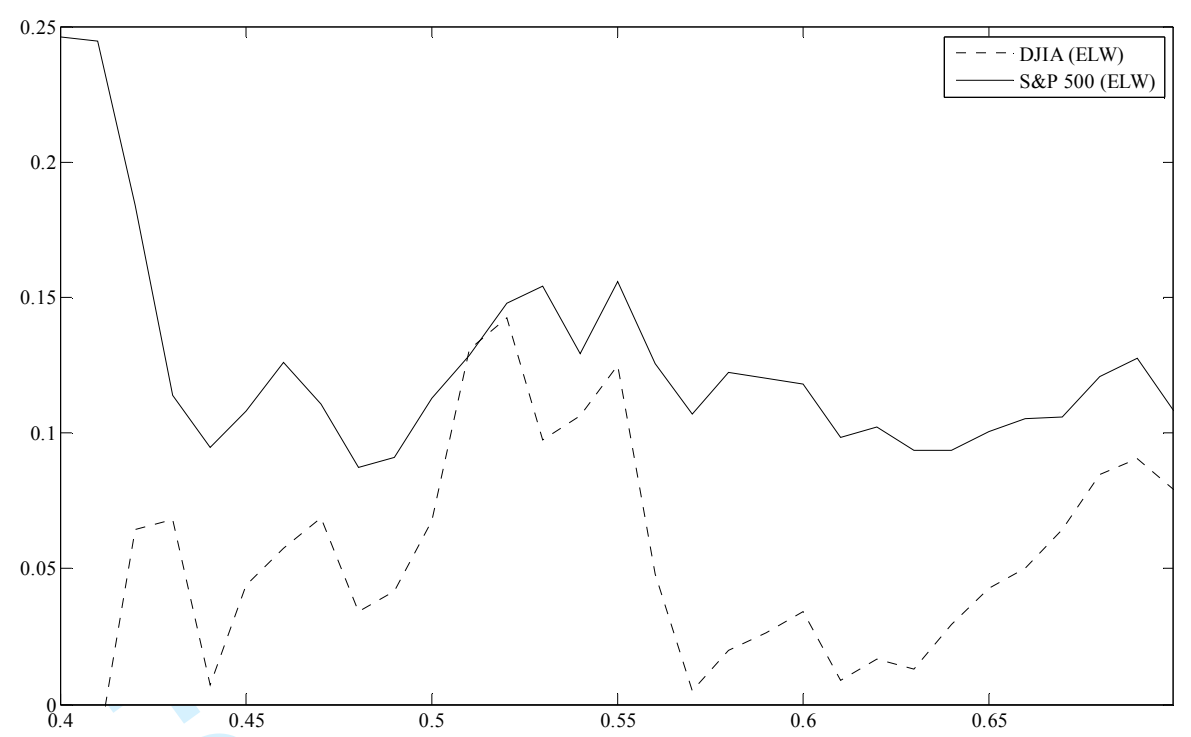

Fig. 3. S\&P 500 and DJIA indices HAR squared residuals ELW fractional differencing parameter estimates 